INSTITUT NATIONAL DE LA STATISTIQUE ET DES ETUDES ECONOMIQUES

Série des Documents de Travail du CREST

(Centre de Recherche en Economie et Statistique)

\title{
$n^{\circ} 2007-29$
}

\section{Anti-Competitive Effects of Resale-Below-Cost Laws}

\author{
M.-L. ALLAIN \\ C. CHAMBOLLE 2
}

Les documents de travail ne reflètent pas la position de l'INSEE et n'engagent que leurs auteurs.

Working papers do not reflect the position of INSEE but only the views of the authors.

\footnotetext{
${ }^{1}$ CNRS, Laboratoire d'Econométrie de l'Ecole Polytechnique, 1 Rue Descartes, 75005 Paris, France and CREST, LEI. (marie-laure.allain@shs.polytechnique.fr)

2 INRA (ALISS, 65 Bld de Brandebourg, 94205 Ivry sur Seine, France and Ecole Polytechnique). chamboll@ivry.inra.fr
} 


\title{
Anti-Competitive Effects of Resale-Below-Cost Laws
}

\author{
Marie-Laure Allain* and Claire Chambolle
}

\begin{abstract}
We show that resale-below-cost laws enable producers to impose price-floors to retailers. This mechanism suppresses downstream competition but also and more surprisingly dampens upstream competition, leading to higher prices and lower welfare. This article also shows that a price-floor implements corner equilibria that are worse for welfare than a resale price maintenance contract. Retailers' buyer power appears as a key element for a price-floor to work out.

\section{Résumé}

Nous montrons que l'interdiction de la revente à perte permet aux producteurs d'imposer des prix-planchers aux distributeurs. Ce mécanisme supprime la concurrence aval, et permet également d'atténuer la concurrence amont. En conséquence, les prix de détail sont plus élevés et le surplus social diminue. Cet article montre également qu'un prix plancher met en œuvre des équilibres en coin encore plus néfastes pour le bien-être social que les prix de revente imposés. La puissance d'achat des distributeurs est déterminante dans le fonctionnement d'un prix plancher.

Jel Codes: L13, L41, L42.

Keywords: Price-floor, Resale Price Maintenance, Buyer Power, Competition.

${ }^{*}$ CNRS, Laboratoire d'Econométrie de l'Ecole Polytechnique (1 rue Descartes 75005 Paris, France, email : marie-laure.allain@shs.polytechnique.fr) and CREST-LEI.

${ }^{\dagger}$ INRA (ALISS: 65 bld de Brandebourg, 94205 Ivry sur Seine, email: chamboll@ivry.inra.fr) and Ecole Polytechnique.

${ }^{\ddagger}$ We thank Denis Gromb, Patrick Rey, and Thibaud Vergé for their helpful comments, as well as the participants of EEA, ESEM, EARIE and IIOC conferences and London Business School, UCBerkeley, Paris and Toulouse seminars. Partial support from the Polytechnique Chair in Business Economics is acknowledged.
\end{abstract}




\section{Introduction}

In most countries, retailers' pricing practices are submitted to the same general competition laws as those of producers. However, during the 1990's, several countries adopted regulations to prevent retailers from engaging in below-cost pricing, or "lossleading". These resale-below-cost laws (henceforth "RBC laws") prevent retailers from setting retail prices below a statutorily mandated level of cost, usually based on the unit price invoiced by the supplier. ${ }^{1}$ Yet in the last decade, professional as well as academic studies have denounced the price-raising effects of these laws, thus calling their relevance into question.

Beyond the analysis of the welfare impact of loss-leading, this article studies an unforeseen but major anticompetitive effect of RBC laws: ${ }^{2}$ We argue that they enable producers to impose price-floors to their retailers. This induces higher prices on the whole range of products sold by retailers and not only on those that would have been sold below cost. Therefore we claim that this price-floor mechanism may explain most of the price effect of RBC laws. More generally, we study the anticompetitive effects of price-floor restraints in a setting where producers and retailers bargain over either linear or two-part tariffs.

This article provides a theoretical framework for this analysis. We consider an industry with upstream and downstream imperfect competition, where two producers sell differentiated products through a duopoly of differentiated retailers. We develop a new setting in order to focus on the real timing of vertical negotiations. In our model, producers first set wholesale prices (i.e. their general terms of sales). These are public and non discriminatory, as required by commercial laws in most countries. Afterwards, producers bargain with retailers over secret rebates. These rebates depict the so-called "backroom margins", which gather diverse fees such as slotting allowances, deferred price reductions or payment for commercial services. In most countries, they account for a growing part of the transfers between producers and retailers (cf. Shaffer, 1991). The crucial point is that, according to the law, these deferred rebates cannot be deducted from the threshold that defines the legal minimum retail price: this threshold will thus be the wholesale price published in the general terms of sales. After these negotiations, retailers set their prices on the final market.

\footnotetext{
${ }^{1}$ For a detailed review of RBC laws in OECD countries, see the OECD report "Resale Below Cost Laws and Regulations", DAF, 02/23/2006. Section 2 outlines some RBC laws and presents empirical studies on their price effects.

${ }^{2}$ For an analysis of the pros and cons of loss leading, see Walsh and Whelan (1999).
} 
In this setting, we first show that the law enables producers to set an industrywide price-floor that suppresses intrabrand competition at the retail level and softens producers' competition, thus leading to higher retail prices. ${ }^{3}$ Retailers set their prices at the price-floor level, and profits are shared between producers and retailers through the negotiated backroom margins. ${ }^{4}$ When buyer power is large enough, a price-floor works out as a Resale Price Maintenance (RPM), but when producer's bargaining power is strong, we show that price-floors implement corner solutions which lead to higher retail prices and lower welfare than a RPM restraint would. In some cases, the price-floor proves to be even more profitable than a RPM for producers.

This article fits in the industrial organization literature on competition policy and vertical restraints (Motta, 2004). Although there is a rather large literature on the anticompetitive effects of RPM, few articles have analyzed price-floors. First, with two-part tariffs, O'Brien and Shaffer (1992) have highlighted the efficiency of pricefloors when downstream competition drives retail prices to a too low level. They show that when an upstream monopoly offers take-it-or-leave-it secret contracts to retailers, they suspect opportunistic renegotiations with their competitors. This rules out any contract with a unit price higher than the marginal cost of production. Downstream competition thus drives final prices to a too low level: the producer needs a pricefloor (or a $R P M$ ) to restore the monopoly price. Our article is more closely related to Rey and Vergé $(2004 i$ ) who take also into account imperfect competition at the upstream level. They consider differentiated producers offering publicly observable two-part tariff contracts to differentiated retailers, and show that a RPM enables manufacturers to neutralize upstream as well as downstream competition and to reach the monopoly profit. With negotiated two-part tariff contracts, we confirm this result. Besides, we show that the range of equilibrium retail prices sustainable with a RPM and a price-floor widens with retailer's bargaining power, and that a RPM may lead to lower equilibrium retail prices than a price-floor.

Even scarcer are the papers analysing price-floors associated to linear tariffs. The

\footnotetext{
${ }^{3}$ In a previous paper, we show that the suppression of downstream competition exists in the simple framework of an upstream monopoly (Allain and Chambolle, 2005).

${ }^{4}$ This price-floor mechanism has been underlined by the French competition authority in two recent cases (on the market for calculators, Conseil de la Concurrence, 03-D-45, 25/09/2003, and on the market for videotapes, 05-D-70, 19/12/2005). In both cases, backroom margins could reach $40 \%$ of the unit price. The Conseil claimed that the producers imposed price-floors to their retailers in order to suppress retail competition on their products. Retailers who tried to set lower prices were called to order by their supplier who reminded them not to trespass the law.
} 
reason is that, as linear tariffs create a double margin effect, retail prices are generally too high and a price-floor restraint may appear useless. However, we show that, with linear tariffs, if retailers have enough bargaining power, retail prices are too low and producers may use price-floors as a RPM, in order to raise prices. Besides, when their bargaining power increases, producers may adopt corner-pricing strategies in order to set binding price-floors that drive retail prices even higher than a RPM would, thus hurting welfare more than a RPM. In all equilibria, price-floors enable producers to suppress downstream competition and to relax upstream competition partially.

Finally, this article fits also in the recent but growing literature on buyer power (for a survey, see Inderst and Mazzarroto, 2006). Most articles in this field analyze the determinants and consequences of buyer power. Our purpose is rather to understand its role on the efficiency of vertical restraints and their welfare consequences. We show that buyer power is a key element that facilitates the use of a price-floor by producers. Furthermore, if competition is rather strong at both levels, the priceraising effect and welfare damage of the price-floor are worse when the retailers have all bargaining power.

To summarize, our four main contributions to the theoretical literature are as follows. First, we show that, although a less restrictive restraint, a price-floor may be more profitable for the producers and more harmful for welfare than a RPM. Second, we show how a price-floor may neutralize downstream as well as upstream competition. Third, we underline the role of buyer power in the efficiency of price-floors. Finally, we shed some light on the anticompetitive effects of RBC laws and provide economic policy recommendations for their reform.

This article proceeds as follows. Section 2 outlines some RBC laws and reviews the empirical literature on their price effects. The model is presented in section 3. Section 4 develops the equilibrium analysis in two benchmark cases: first with no legal restriction, second with $R P M$ contracts. Section 5 points out the anticompetitive effects of the law. We discuss the effect of competition on the equilibrium outcomes in section 6 , explore some extensions in section 7 and conclude in section 8 . 


\section{RBC laws}

\subsection{Why RBC laws?}

In most countries, RBC laws were adopted in a context of growing retail market concentration, which considerably strengthened the market power of a few large retail chains. The changes in the competitive structure of the retail sector have deeply transformed the balance of power between producers and retailers, and retailer's buyer power has become a major issue for competition policy. ${ }^{5}$ RBC laws were in most cases an answer to the lobbying of producers and small retailers who complained about the adverse effects of loss-leading practices by large retail chains. On the one hand, small retailers argue that below-cost pricing is predatory: Loss-leading would enable large retail chains to drive out smaller competitors and benefit afterwards from a less competitive environment. On the other hand, loss-leading practices are also criticized by producers, as loss-leading by one retailer may toughen the negotiations with other retailers who may require lower wholesale prices in order to match their rival's price.

In theory, anti-predatory legislation should be sufficient to prevent harmful and predatory loss-leading practices. Yet competition authorities in most countries deal with predatory pricing without per se rules. Generally, the comparison to the firm's average variable cost is not sufficient for a price to be deemed predatory. In the EU, competition authorities must also prove that the firm has a dominant position. In the US, the court must prove that the retailer could not recoup the losses incurred by pricing below-cost without the elimination of a competitor. ${ }^{6}$ This being very hard to prove, retailers are rarely condemned for predatory pricing practices. ${ }^{7}$ Therefore RBC laws have been rather widely enacted: as per se rules, they are easier to enforce, and under such laws a below-cost price can be condemned without any further condition. The following section provides an overview of existing RBC laws in several countries.

\subsection{Legal overview}

In Europe, RBC laws are rather widespread. RBC laws exist in Belgium, France, Italy, Luxembourg, Portugal and Spain, as well as in Greece and Ireland for grocery

\footnotetext{
${ }^{5}$ For empirical evidence, see OECD (1999) and EC (1999).

${ }^{6}$ Brooke Group vs. Brown \& Williamson Tobacco, 509 U.S. 209 (1993).

${ }^{7}$ In 1993 however, Wal-Mart was condemned for having set too low prices on pharmaceutical products in Arkansas.
} 
goods and Hungary for agricultural products. In two of the European countries where the legislation seems to be the most restrictive, France and Ireland, these laws are currently under reform. In Germany, there is no specific RBC law, but the antitrust law simplifies the application of anti-predatory regulation to the retail sector. ${ }^{8}$

The French Galland Law, the Spanish Law on Unfair Competition (both enacted in 1996) and the 1987 Irish Groceries Orders use very close definitions of the cost threshold. The Irish Groceries Orders, for instance, stipulate that "a retailer shall not sell grocery goods at a price that is less than the net invoice price of the goods $[. .$.$] The net invoice price [...] shall be calculated having regard to an invoice relating$ to the delivery of like goods by the supplier to the retail store concerned which is of the same date with the sale of goods [and] net of any allowance or refund that is allowable on the return of the goods' container, and no account shall be taken of discounts, rebates or other deductions which are not entered on the invoice in cash terms as deductions from the sum due to the supplier" (art. 11). Note that this "net invoice price" excluding retailing costs and deferred discounts is different from the average variable cost used to identify predatory pricing.

In the US, there is no federal law prohibiting below-cost sales. Many US States however have some type of RBC laws: twenty-five States have laws that apply generally to all retail sales, and thirty one have specific laws that apply to the sales of products such as gasoline, tobacco, alcohol or dairy products. The definition of the cost benchmark varies, but most State laws set it at the acquisition price, possibly plus a required retail margin. Enforcement of these laws also varies among states, but in most cases they are likely to be a restriction on retail pricing decisions. ${ }^{9}$

\subsection{Adverse effects of RBC laws}

In the US, there is no evidence that RBC laws affect market outcomes in a clear way. Studies comparing retail gas prices between States with and without RBC laws

\footnotetext{
${ }^{8}$ The German law states that any retailer with "considerable market power" (and no necessary dominant position) must not sell a product below its purchase price. Deferred rebates are excluded from the cost benchmark. Hence in 2000 the Cartel Office condemned Wal-Mart, Aldi and Lidl, three major supermarket chains, for selling milk and butter at below-cost prices. The German Supreme Court confirmed that the rule applies whether or not there is any harm to competition.

${ }^{9}$ In contrast to the treatment of predatory pricing claims under federal antitrust laws, where plaintiffs must show that the defendant's price cut is likely to harm consumers, a plaintiff can prevail under these laws even if there is no proof of harm to competition.
} 
conclude in general to a price-raising effect of the laws (Calvani, 1999; Johnson, 1999). Among other recent studies of gasoline-specific RBC laws, Anderson et al. (1999) find that they are associated with higher gasoline prices and higher retail margins. Yet they also find that these higher margins attract entry and that there are more gasoline retail outlets in the States with gasoline-specific laws. In contrast, Skidmore et al. (2005) find evidence that the laws are associated with lower long-run gasoline prices: these results support the idea that $\mathrm{RBC}$ laws help maintain a fair competitive environment by fighting against predatory practices. However, these empirical findings have to be taken with caution as vertical integration is widespread in the gasoline sector, and because of the inability to control for the vigor of enforcement of the law.

In Europe, there is a consensus among empirical studies of general RBC laws to conclude to their price-raising effects. In France, since the enforcement of the Galland law, supermarket prices increased at a significantly larger rate than in other EU countries (Canivet, 2004). In Ireland, the Central Statistics' Office has pointed out that retailers' margins have increased from $15.8 \%$ in 1988 to $20.1 \%$ in 1993 . Moreover, an econometric study by Collins et al. (2001) showed that the 1987 Groceries Order clearly had a significant positive influence on retail gross margins. This shows that retail competition has been weakened by the RBC law.

In theory, that RBC laws lead to higher prices is not surprising for several reasons. First, there is an immediate positive effect on the prices of the former loss-leaders. This price increase may anyway be compensated by a reduction in the prices of other products. Second, if these laws aim at limiting predatory pricing by large retail chains, their purpose is to relax short term competition in order to protect long term competition: The short term effect may well increase prices. However, the following model puts forward the idea that the main price-raising effect is somewhere else. It may indeed rely on a vertical adverse effect of the law that enables the producers to relax both downstream and upstream competition through a price-floor mechanism.

\section{The model}

\subsection{Assumptions}

Two producers, $A$ and $B$, produce two horizontally differentiated goods, also branded $A$ and $B$, at zero marginal cost of production. Each producer can market his good through two differentiated retailers, 1 and 2, competing in prices to sell the products 
to consumers. Apart from the transfer they pay producers, retailers incur a constant marginal retailing cost which we normalize to zero.

We assume that consumers differ in their preferences for retailers as well as products. If each retailer carries both brands, there are in effect four imperfect substitute goods on the market. We denote $q_{K i}$ the quantity and $p_{K i}$ the price of good $K$ $\in\{A, B\}$ sold by retailer $i \in\{1,2\}$ (henceforth good $K i$ ). The inverse demand for good $K i$ is assumed to be:

$$
p_{K i}=1-q_{K i}-a q_{L i}-b q_{K j}-c q_{L j} \text { with } i \neq j \text { and } K \neq L .
$$

Parameter $a \in[0,1]$ measures the degree of substitutability between the products (interbrand competition): the brands $A$ and $B$ become closer substitutes when $a$ increases. Similarly, $b \in[0,1]$ is the degree of substitutability between the retailers (intrabrand competition). Finally, parameter $c$ measures the degree of substitutability between the two different brands sold by two different retailers. For simplicity, we assume $c=a \cdot b \cdot{ }^{10}$ Note that when $a=0$ the demands for the two brands are independent, and so are the demands at the two retailers' when $b=0$. We denote by $D_{K i}\left(p_{K i}, p_{K j}, p_{L i}, p_{L j}\right)$ the demand for good $K i$ when the four products are sold.

The timing is as follows:

- Stage 1: Producers simultaneously publish non discriminatory wholesale unit prices $w_{A}$ and $w_{B}$.

- Stage 2: Producer $K$ and retailer $i(K \in\{A, B\}, i \in\{1,2\})$ negotiate backroom margins in the form of a unit rebate, i.e they negotiate over the effective wholesale unit price (henceforth "net transfer") $t_{K i}{ }^{11}$ The four bilateral negotiations are assumed to be secret and simultaneous. We describe the details of the bargaining stage and of the solution concept in section 3.3.

- Stage 3: Retailers simultaneously set prices $p_{A 1}, p_{A 2}, p_{B 1}$, and $p_{B 2}$.

\footnotetext{
${ }^{10}$ The underlying assumption is that a representative consumer has a quadratic utility function and a budget of 1: $U(q)=\sum_{K, i} q_{K i}-\frac{1}{2} \sum_{K, i} q_{K i}^{2}-a \sum_{i} q_{A i} q_{B i}-b \sum_{K} q_{K 1} q_{K 2}-c \sum_{K} q_{K 1} q_{L 2}$. This fairly standard representation of consumers' preferences takes into account intra- as well as inter-brands competition (Dobson and Waterson, 1996). Assuming $c=a . b$ is sufficient for the utility to be concave; it boils down to assume that the substitutability between a product sold by one retailer and the other product sold by the other retailer is a combination between intrabrand and interbrand substitution. Choosing another value for $c$ such that the utility function is concave would not qualitatively alter our results. Note that parameters $a$ and $b$ are not perfect proxies for the degree of inter- and intrabrand competition. Indeed, given a system of symmetric prices, the demand for each good decreases with both parameters. See Rey and Vergé (2004) for a discussion.

${ }^{11}$ In section 7.1 we develop the same analysis with two-part tariffs.
} 


\subsection{Comments}

With regard to stage 1 , our main assumption is that of non discriminatory pricing. As we consider two symmetric retailers, i.e. similar firms offering the same service to producers, this assumption is conform with most competition laws: Price discrimination is generally lawful if it reflects the different costs of dealing with different customers, but not if it applies to similar ones. ${ }^{12}$ In particular, our model fits well the French and Irish situations, where the general terms of sale of any product must be public and non-discriminatory, insofar as retailers offering the same service must be offered the same conditions by a producer. Here we simplify the general terms of sales to a unit price $w_{K}$ that we assume to be non discriminatory.

Our model's main novelty is the renegotiation in stage 2. We assume that after the producers have published their general terms of sales (stage 1), each retailer can bargain with each supplier over secret backroom margins (stage 2). These renegotiations allow for discriminatory wholesale tariffs, and therefore may lead to opportunism problems (McAfee and Schwartz, 1994). This assumption is in contrast with the standard literature on vertical relationships between producers and retailers (e.g. Rey and Tirole, 1986). It is, however, in line with practice in many cases. First, in practice, firms do negotiate rebates. We use the term "backroom margins" to refer to the variety of forms such rebates can take, i.e. a complex set of price reductions and transfers, including slotting fees, new product introduction fees, pay-to-stay allowances, and retribution for retailers' sales efforts. Studies on French data suggest that such backroom margins can reach $60 \%$ of the unit price invoiced (Canivet, 2004). Second, these rebates are generally compatible with the legal prohibition of discriminatory pricing: Most of them are meant to compensate a retailer for a sales effort, which is difficult to verify. Given this opaqueness, there is widespread suspicion that rebates do not reflect actual services provided by the retailer. Therefore we assume that no service is provided. Third, many rebates are paid to a retailer after some delay, for instance at year end: We model the rebates as deferred reductions in the

\footnotetext{
${ }^{12}$ More precisely, in the US, "a seller charging competing buyers different prices for the same commodity [...] may be violating the Robinson-Patman Act" as "this kind of price discrimination may hurt competition by giving favored customers an edge in the market that has nothing to do with superior efficiency" (FTC). Within the EU, price discrimination through which firms "apply dissimilar conditions to equivalent transactions with other trading parties, thereby placing them at a competitive disadvantage" may constitute an abuse of dominant position (Art. 81 of the EC Treaty). For a discussion on the welfare effects of banning price discrimination, see Caprice (2006).
} 
unit wholesale price and assume that they cannot be accounted for in the loss-leading price threshold. ${ }^{13}$ That is, under the RBC law, a retailer must not set the price of good $K$ below $w_{K}$, even though the actual unit price paid by retailer $i$ is only $t_{K i}$. Thus, the total margin of the retailer (the difference between the unit resale price and the unit price really paid to the producer) may be split up into "observable margin" (the difference between the resale price and the unit wholesale price invoiced) and "backroom margin" (the amount of the rebates paid by the producer to the retailer).

\subsection{Bargaining assumptions and solution concept}

In stage 2, simultaneous and secret bilateral negotiations by four producer-retailer pairs yield four transfers: $t_{A 1}, t_{A 2}, t_{B 1}$, and $t_{B 2}$. Negotiations within each pair is modeled as a Nash bargaining in which the producer's bargaining power is $\alpha \in[0,1]{ }^{14}$ Note that both producers have the same bargaining power $\alpha$, and both retailers $1-\alpha$. Default options correspond to the retailer not distributing the producer's brand. We assume that the outcome of the stage 2 negotiation between two firms is not observable by other firms. ${ }^{15}$ However, before the beginning of stage 3, each retailer gathers the information from his two negotiations with the two suppliers. Besides, consumers are perfectly informed about the availability and prices of all the products.

We look for symmetric Contract Equilibria in pure strategies (Crémer and Riordan, 1987 ; O'Brien and Shaffer, 1992). In a Contract Equilibrium, each set of net transfer must be immune to profitable bilateral renegotiation by a producer-retailer pair, taking the other three net transfers as given, including those defined by a negotiation in which one of them is involved. In particular, this implies that the firms

\footnotetext{
${ }^{13}$ This assumption is crucial. We discuss its role in section 6.2 and show that the price-raising effect of the law would be suppressed were the retailers allowed to integrate negotiated rebates in the price threshold.

${ }^{14}$ For simplicity, we model the negotiations as one stage, but formally the extensive form of each of the four negotiations is the bargaining game of Binmore, Rubinstein and Wolinsky (1986): the two negotiators of a pair alternate making offers to one another until they reach an agreement, and after an offer is rejected there is an infinitesimal probability of a breakdown in the negotiation. It is well known that as the probability of breakdown becomes arbitrarily small, a pair will immediately agree on the Nash bargaining solution. Stage 2 ends when the four negotiations have led to either an agreement or a breakdown. This use of the Nash bargaining game is fairly standard: see de Fontenay and Gans (2005) for another modeling of multilateral negotiations where each pair negotiates also in the manner specified by Binmore et al. (1986).

${ }^{15}$ We discuss the role of this assumption more precisely in section 7.3.
} 
have passive beliefs, i.e. if say a producer received an unexpected offer from a retailer, this would not affect his beliefs about the outcome of the three other negotiations, including those in which he or the retailer in question are involved. Furthermore, this equilibrium concept focuses on pairwise deviations and does not consider multilateral deviations. One way to think about this solution concept is to imagine that each producer and each retailer sends a different agent to each negotiation and that the two agents of a given producer or retailer cannot communicate with each other while negotiating. ${ }^{16}$

We will analyze three cases. In section 4, we study two benchmark cases: we solve the game assuming first no legal restriction on pricing, and second assuming that producers can impose resale-price maintenance $(R P M)$ contracts to the retailers. Then in section 5 we consider the effect of the RBC law, and we compare this case to the two benchmarks. In sections 4 and 5, we analyze the role of the exogenous bargaining power parameter $\alpha$. Next we develop in section 6 a comparative statics analysis in order to assess the effects of substitution parameters $a$ and $b$ on all equilibrium outcomes.

\section{Benchmarks}

\subsection{No restriction on resale prices}

We solve the model first assuming there is neither RBC law, nor any kind of contract or vertical restraint that may restrict the retailers' pricing decisions. We refer to this basic situation as the no-restriction case. The corresponding equilibria are denoted by the superscript " $*$ ". The characterization of these equilibria is derived formally in appendix $A 1$. Here, we present the main intuitions.

Lemma 1 In any no-restriction equilibrium, net transfers are $t_{K i}^{*}=\frac{2 \alpha(1-a)}{4-2 a \alpha-b(2-\alpha)}$, and retail prices are $p_{K i}=p^{*}=\frac{2(1-b)+\alpha(1-2 a+b)}{4-2 a \alpha-(2-\alpha) b}$.

First, notice that retail prices chosen in stage 3 do not depend on the wholesale prices $w_{K}$ set in stage 1 , but only on the net transfers decided in stage 2 . Second,

\footnotetext{
${ }^{16}$ This assumption is known as "schizophrenia of the negotiator". Contract Equilibrium concept is a refinement of that of Perfect Bayesian Equilibrium that includes passive beliefs and "schizophrenia of the negotiator". Relaxing the assumption of schizophrenia allows for multilateral deviations which may threaten the existence of equilibria (Rey and Vergé, 2004(i) and (ii) and Segal, 1999).
} 
notice that the wholesale prices $w_{K}$ do not affect the negotiations over the net transfers $t_{K i}$. Therefore the wholesale prices $w_{K}$ chosen in stage 1 are immaterial to the net transfers negotiated in stage 2 and ultimately to the retail prices chosen in stage 3 . In that respect, these wholesale prices have no commitment value. A direct implication is that while equilibrium net transfers and retail prices are unique, they correspond to a continuum of wholesale prices. Among this continuum of equilibrium wholesale prices, some involve loss-leading from the retailers, according to the legal definition $\left(w_{K} \geq p^{*}\right)$, and others do not $\left(w_{K} \leq p^{*}\right)$. Here, the practice of loss-leading is neutral with respect to prices, profit sharing and consumers' surplus.

A comparative statics analysis highlights the impact of the producers' bargaining power on the equilibrium outcome.

Proposition 2 The no-restriction equilibrium net transfers $t_{K i}^{*}$ and retail prices $p^{*}$ strictly increase in $\alpha$.

The retail price $p_{K i}$ set in stage 3 increases with the retailer's unit cost, i.e. with the net transfer $t_{K i}$. Consider the stage 2 negotiation between producer $K$ and retailer $i$ over $t_{K i}$, given the three other net transfers. Increasing $t_{K i}$ has two effects: it increases the producer's margin, i.e. his profit per unit of good $K i$ sold, but, as it also leads to an increase in the retail price $p_{K i}$, it reduces demand for that good. However, in the neighborhood of the equilibrium, the direct effect on the producer's margin dominates, therefore an increase in the net transfer $t_{K i}$ raises the incremental profit made by producer $K$ by selling his product to retailer $i$ (i.e. $\Pi_{K}-\Pi_{K}^{3}$, see Appendix A1). Conversely, the incremental profit $\left(\Pi_{i}-\Pi_{i}^{3}\right)$ made by retailer $i$ by dealing with $K$ decreases in the net transfer $t_{K i}$. Yet the larger $\alpha$, the more weight is applied in the negotiation to the producer's incremental profit, to the detriment of the retailer's. Therefore the equilibrium net transfer strictly increases with the producers' bargaining power $\alpha$. In turn, the double margin effect implies that the final price $p^{*}$ increases with retailers' unit costs, i.e. with the net transfers to their suppliers, and thus with the producers' bargaining power $\alpha .{ }^{17}$

Notice that the producers' margin and profit go to zero when $\alpha$ goes to zero, but that the retailers' margin and profit remain strictly positive when $\alpha$ goes to 1 . This asymmetry stems from the sequential timing of the game. Consider first $\alpha=0$. The retailers have all the bargaining power, and they also enjoy the follower advantage.

\footnotetext{
${ }^{17}$ Proposition 1 holds in a more general setting for a broad range of demand functions (see appendix A.1.4 for a discussion).
} 
As a consequence, stage 2 negotiations lead to zero margins and no profit for the producers, whereas the retailers get all the profit. There is no double margin: This is as if each retailer were vertically integrated with both producers and got both brands at zero cost. However, for $\alpha$ close to 1 , the producers cannot extract the full surplus as after the stage 2 negotiations, the retailers can still set strictly positive margins in stage 3 , and get strictly positive profit. For $\alpha \in(0,1]$, both upstream and downstream firms set positive margins and the double margin inefficiency increases in $\alpha$.

The firms' bargaining power also influences their profits. As expected, the retailers' profits decrease in $\alpha$. More surprisingly, the producers' profits do not always increase in $\alpha$ : When interbrand competition is weak and intrabrand competition strong $(b \geq 2 a)$, the producers' profits first increase and then decrease with $\alpha$. This stems from the modeling of bargaining: In a contract equilibrium, a producer does not fully internalize the effect of his bargaining with a given retailer on the profit he realizes with the other retailer. This tends to increase net transfers and retail prices, and may reduce the producers' profits. ${ }^{18}$ Finally, the effect of $\alpha$ on total profits is ambiguous. Double margin may increase joint profit by relaxing competition at both levels, as long as retail prices remain lower than the monopoly price. However, when $\alpha$ is very large, double margin may drive prices too high and reduce joint profit. Therefore total industry profits need not be monotonic in $\alpha$. If $b$ is small and $a$ large, total profits increase in $\alpha$, but otherwise, total profits first increase and then decrease in $\alpha$.

\subsection{RPM contracts}

Assume now that the producers are able to use non discriminatory Resale Price Maintenance contracts $(R P M)$, i.e. to impose retail prices. This amounts to assuming that retailers must set retail prices $p_{K i}=w_{K}$ in stage 3 . The superscript " " denotes the equilibrium outcomes in the $R P M$ case. The characterization of these equilibria is derived formally in Appendix A2.

First, we determine the negotiations' outcome in stage 2. All firms know the unit prices $w_{K}$ decided in stage 1 and the retail prices $p_{K i}=w_{K}$. The resolution of the four Nash conditions gives the following unique interior solution $t_{K i}\left(w_{K}, w_{L}\right)^{19}$ :

$$
t_{K i}\left(w_{K}, w_{L}\right)=\alpha \frac{\left(1-a^{2} \alpha-(1-\alpha) b\right) w_{K}-a(1-\alpha)(1-b) w_{L}}{(1-(1-\alpha) b)^{2}-a^{2} \alpha^{2}}
$$

\footnotetext{
${ }^{18}$ See a discussion of this effect in Appendix $A 1$.

${ }^{19}$ Defined by continuity, for $\alpha=1$ and $a=1$ : $t_{K i}\left(w_{K}, w_{L}\right)=w_{K}$; and for $\alpha=0$ and $b=1$, $t_{K i}\left(w_{K}, w_{L}\right)=0$.
} 
Anticipating these net transfers, the producers determine the optimal $R P M$ price in stage 1 as follows.

Lemma 3 Under RPM, there is a unique equilibrium: wholesale prices are $w_{K}=$ $\widetilde{w}=\frac{1-a^{2} \alpha-b+\alpha b}{2+a \alpha-a^{2} \alpha-2(1-\alpha) b}$, the net transfers are $t_{K i}=\widetilde{t}=\frac{\alpha(1-a)\left(1-a^{2} \alpha-(1-\alpha) b\right)}{(\alpha((1-a) a+2 b)+2(1-b))(1-b+\alpha(b-a))}$, and retail prices are $p_{K i}=\widetilde{w}$.

As under no-restriction, the net transfers $\tilde{t}$ increase with $\alpha$ because the producers' margin increases with their bargaining power. ${ }^{20}$ However profit sharing is different from the no-restriction case. When $\alpha=0$, retailers negotiate maximum rebates so that producers have zero margin and zero profit, as in the no-restriction case. When $\alpha$ is strictly positive, however, retailers' share of total profits is less than in the norestriction case. Not being free to choose retail prices in stage 3 reduces their status$q u o$ profits in stage 2 negotiations. Besides, once the net transfer is determined in stage 2 , they no longer benefit from the follower advantage they had in the no-restriction case, and this further reduces their profits: For $\alpha=1$, they get zero margin, and the producers get all the profit. Contrary to the no-restriction equilibrium, the wholesale prices and net transfers in the $R P M$ equilibrium are uniquely defined: there is now a commitment in stage 1 , as the wholesale price $\widetilde{w}$ defines the retail price.

Let us now study the retail prices in the $R P M$ equilibrium.

Proposition 4 Under $R P M$, the equilibrium retail prices $p_{K i}=\widetilde{w}$ decrease with the producers' bargaining power $\alpha$. For $\alpha=0$, equilibrium retail prices are the monopoly price $p_{K i}=1 / 2$, and for $\alpha=1$, the equilibrium retail prices are the prices that would be chosen by vertically integrated producers, each selling two differentiated products : $p_{K i}=\frac{1-a}{2-a}$.

The intuition is as follows. Consider the case $\alpha=1$. The producers have all the bargaining power, so that the net transfers negotiated in stage 2 are equal to the retail price. In that case, the producers behave as two vertically integrated firms, each selling two differentiated products $K 1$ and $K 2$. Retail prices thus account for the degree of competition between producers, but not for that between the retailers, which is internalized. Note that each producer is able to maximize the profit of the vertically integrated structure he would form with his two retailers, but he cannot achieve the industrywide monopoly profit, as the upstream sector remains competitive: complete

\footnotetext{
${ }^{20}$ Again, this property holds for a broad range of demand functions.
} 
collusion prices, or prices chosen by an integrated monopoly owning both products as well as both outlets ("industrywide monopoly"), would be $p_{K i}=\frac{1}{2}$.

As $\alpha$ decreases, the retailers claim for a larger share of total profits. When producer $K$ sets the retail price $w_{K}$ in stage 1 , he must consider two effects. On the one hand, given $w_{L}$, a marginal increase of the retail price $w_{K}$ increases his margin $t_{K i}$ (Cf. (2)). On the other hand, this also reduces the total demand for product $K$. When $\alpha$ is smaller, retailers claim a higher margin at the expense of the producers', so that the positive effect of raising $w_{K}$ on the producer's margin becomes relatively more important than the negative effect on demand. Producers thus raise retail prices. ${ }^{21}$

Proposition 5 RPM contracts internalize intra-brand competition irrespective of the firms' bargaining powers. RPM contracts also reduce interbrand competition, and this dampening effect increases in retailers' buyer power.

\section{Proof: Straightforward from proposition 2.}

Under $R P M$, buyer power reduces competition between the producers, who increase their prices towards the collusive price in order to maximize the profits they share with the retailers. The more buyer power the retailers have, the more they are able to reduce upstream competition. As a consequence, the total profit of the industry decreases with $\alpha$. For $\alpha=0$, the outcomes are those of a perfectly collusive industry: the $R P M$ eliminates downstream competition, and buyer power eliminates upstream competition. In that case, producers make zero profits, and retailers extract all the profit.

We now compare the equilibrium retail prices and welfare under $R P M$ to those in the no-restriction case.

Remark 1 Retail prices are higher and welfare lower under RPM contracts that in the no-restriction case when retailers enjoy a strong bargaining power.

\section{Proof: see Appendixes A2 and A5.}

When the producers' bargaining power is weak, the no-restriction retail price $p_{K i}^{*}$ is rather low because the retailers' bargaining power reduces double-marginalization, whereas the $R P M$ price is high because the reduction of upstream competition is more

\footnotetext{
${ }^{21}$ This result also holds in a more general setting, for a broad range of demand functions. A sufficient condition is that demand for good $K i$ and the net transfer are concave in the final price $w_{K}$, and that the derivative of the net transfer w.r.t the final price is positive and decreases in $\alpha$.
} 
stringent when buyer power is large. Therefore final prices are higher under $R P M$ than in the no-restriction case when retailer's bargaining power is strong enough: $\widetilde{w}>$ $p_{K i}^{*} \Leftrightarrow \alpha<\alpha_{I}$. Furthermore, in our model, as the firms' costs are normalized to zero, total welfare is inversely related to retail prices (see appendix A-5). Consequently, when $\alpha<\alpha_{I}, R P M$ contracts induce a welfare loss. If retailers' bargaining power is high, $R P M$ contracts create a strong reduction in competition that increases joint profits but induces an even larger reduction of consumers' surplus. In contrast, when $\alpha$ is large, the double marginalization would lead to too high retail prices in the norestriction equilibrium. In that case, the $R P M$ improves social welfare by suppressing the double marginalization.

\section{The effects of a RBC law}

We turn back here to the framework of $R B C$ laws. As they forbid the retailers to set retail prices below, but not above, the unit price $w_{K}$, they enable the producers to use price-floor contracts. In this setting $w_{K}$ works out as an industrywide price-floor for producer $K$, as the $R B C$ law imposes the constraint $p_{K i} \geq w_{K}$ in stage 3 of the game, for $K \in\{A, B\}$ and $i \in\{1,2\}$. We first determine in section 5.1 the equilibria of the game when producers may use price-floor contracts, before comparing them to those of the no-restriction case in section 5.2 and to the $R P M$ case in section 5.3.

\subsection{Price-floor equilibria}

We show here that a price-floor implements $R P M$ prices in equilibrium when the retailers enjoy a strong bargaining power, but leads to corner equilibria with higher retail prices when the producers' bargaining power is strong enough.

The price-floor implements the $R P M$ equilibrium When the price-floor set in stage 1 is binding, it works out as a $R P M$ : in stage 3 , retailers set prices $p_{K i}=w_{K}$, which are perfectly anticipated in stage 2 . Therefore the $R P M$ equilibrium is a natural candidate for the price-floor equilibrium. However, a price-floor can fail to be binding, and therefore to implement the $R P M$ equilibrium: deviations may be profitable at each stage of the game. Potential deviations are (1) for a retailer to deviate in stage 3 by setting a retail price above the wholesale price, and (2), for a producer to deviate by setting a lower wholesale price in order to enable the retailers to undercut his rival. 
Lemma 6 The $R B C$ law enables the producers to implement the RPM equilibrium for any $\alpha$ less than a threshold $\widetilde{\alpha}=\frac{1+a^{2}-2 b^{2}-\sqrt{1+2 a^{2}+a^{4}-8 a^{2} b+4 a^{2} b^{2}}}{2\left(2 a^{2}-b-b^{2}\right)}$.

Proof : see appendix A3.1.

Retailers do not deviate as long as the producers' bargaining power is not too high, but for higher values of $\alpha$ they set retail prices above a price-floor set to the $R P M$ price $\widetilde{w}$. The intuition is as follows. Assume that both producers have set the wholesale price $\widetilde{w}$ in stage 1 . For a retailer, increasing a retail price involves a tradeoff between margin and quantity sold. First consider the case $\alpha=0$. Retailers have all the bargaining power, and they negotiate a net transfer $\widetilde{t}_{K i}=0$ : Their margin is maximum. Furthermore the price-floor is very high: $\widetilde{w}=1 / 2$ is the monopoly price. Therefore, assuming that the transfers are fixed and that her competitor respects the constrained retail prices, a retailer wishes to reduce her retail prices in order to increase her demand and profit: Without the law her best response price would be less than $\widetilde{w}$. The price-floor is thus binding. In contrast, when producers have most of the bargaining power $(\alpha \rightarrow 1)$, retailers' margins go to zero, and the price $\widetilde{w}$ is lower. In that case, each retailer prefers to increase retail prices above $\widetilde{w}$, in order to increase her margin and profit, even at the expense of a reduction in demand. The price-floor set at the $R P M$ level is no longer binding. We show in the appendix that there exist a threshold $\widetilde{\alpha}$ such that retail prices will indeed be constrained by a price-floor if and only if $\alpha \leq \widetilde{\alpha}$. Besides, we show that for any $\alpha \leq \widetilde{\alpha}$, there is no profitable deviation from setting $w=\widetilde{w}$ in stage 1 for a producer.

When $\alpha \geq \widetilde{\alpha}$, a price-floor set to $\widetilde{w}$ would no longer be binding, but retailers may still be constrained in stage 3 in two cases: either producers increase the price-floor in stage 1 , or the negotiation of the net transfers in stage 2 leads to a corner solution such that retailers' unit costs are low enough for their retail prices to be constrained. We analyze these two scenarii in turn and show that both may happen in equilibrium.

The corner price-floor equilibrium As long as producers' bargaining power is not too high above $\widetilde{\alpha}$, producers may implement a first type of corner solution by increasing the wholesale prices $w_{A}$ and $w_{B}$ in stage 1 to the minimum level such that retailers remain constrained in stage 3 . Negotiations in stage 2 lead to the net transfers defined by (2) and the stage 3 constraint is binding.

Lemma 7 For $\widetilde{\alpha} \leq \alpha \leq \bar{\alpha}=\frac{2-b}{3-b}$, there exists a price-floor equilibrium where $w_{A}=$ $w_{B}=\bar{w}=\frac{1-a \alpha-b(1-\alpha)}{2-\alpha(1+a-b)-b}$ and net transfers are defined by (2). 


\section{Proof: see Appendix A3.2.}

Note that $\bar{w}$ increases with producers' bargaining power: As $\alpha$ increases, the net transfers $t_{K i}$ increase, so that retailers' costs and best response prices increase and it becomes more difficult to constrain retailers' pricing decision. When the producers' bargaining power is slightly above $\widetilde{\alpha}$, increasing the unit price to $\bar{w}$ is sufficient for the producers to guarantee that retailers will be constrained in stage 3. However, when $\alpha$ further increases $(\alpha \geq \bar{\alpha})$, the price $\bar{w}$ becomes too high and each producer has unilateral incentives to deviate towards a lower wholesale price. Such a deviation leads to a corner solution in stage 2 negotiations such that retail prices are still constrained for both products, and the deviating producer benefits from an increased market share. This deviation becomes profitable for $\alpha \geq \bar{\alpha}$.

The corner transfer equilibrium For $\alpha \geq \bar{\alpha}$, there exists a price-floor equilibrium where the producers keep the wholesale price constant, equal to $\widehat{w}=\bar{w}(\bar{\alpha})$, and stage 2 negotiations lead to a corner solution such that retailers' unit costs are low enough for their retail prices to be constrained in stage 3 .

Lemma 8 For $\bar{\alpha} \leq \alpha \leq \widehat{\alpha}=\frac{4-2 b}{4-b}$, there exists a price-floor equilibrium where $w_{A}=$ $w_{B}=\widehat{w}=\frac{3-2 a-2 b+a b}{(2-a)(2-b)}$ and negotiations lead to corner-solution transfers $\widehat{t}=\widehat{w}(2-b)-$ $1+b$.

\section{Proof: see Appendix A3.3}

These equilibrium outcomes are independent of $\alpha$. The parameter $\alpha$ nonetheless determines the interval $[\bar{\alpha}, \widehat{\alpha}]$ where the corner transfer defines an equilibrium. For smaller values of $\alpha$, these strategies do not implement an equilibrium because in stage 2, each pair would be better off deviating towards a lower unit transfer. Conversely, for $\alpha \geq \widehat{\alpha}$, each pair deviates towards a higher unit transfer that releases the stage 3 constraint. Therefore no price-floor equilibrium exists for $\alpha \geq \widehat{\alpha}$.

\section{All price-floor equilibria}

Proposition 9 Under the RBC law, a price-floor equilibrium exists if retailer's bargaining power is strong enough, i.e. for any $\alpha \leq \widehat{\alpha}=\frac{4-2 b}{4-b}$.

Proof: straightforward from lemmas 6 to 8 . 
The bold line in Figure 1 below represents the retail price in the price-floor equilibria $\begin{cases}\widetilde{w} & \text { if } \alpha \leq \widetilde{\alpha} \\ \bar{w} & \text { if } \widetilde{\alpha}<\alpha \leq \bar{\alpha} \quad \text { for } \alpha \in[0,1] \text { when } a=b=0.5 . \\ \widehat{w} & \text { if } \bar{\alpha}<\alpha \leq \widehat{\alpha}\end{cases}$

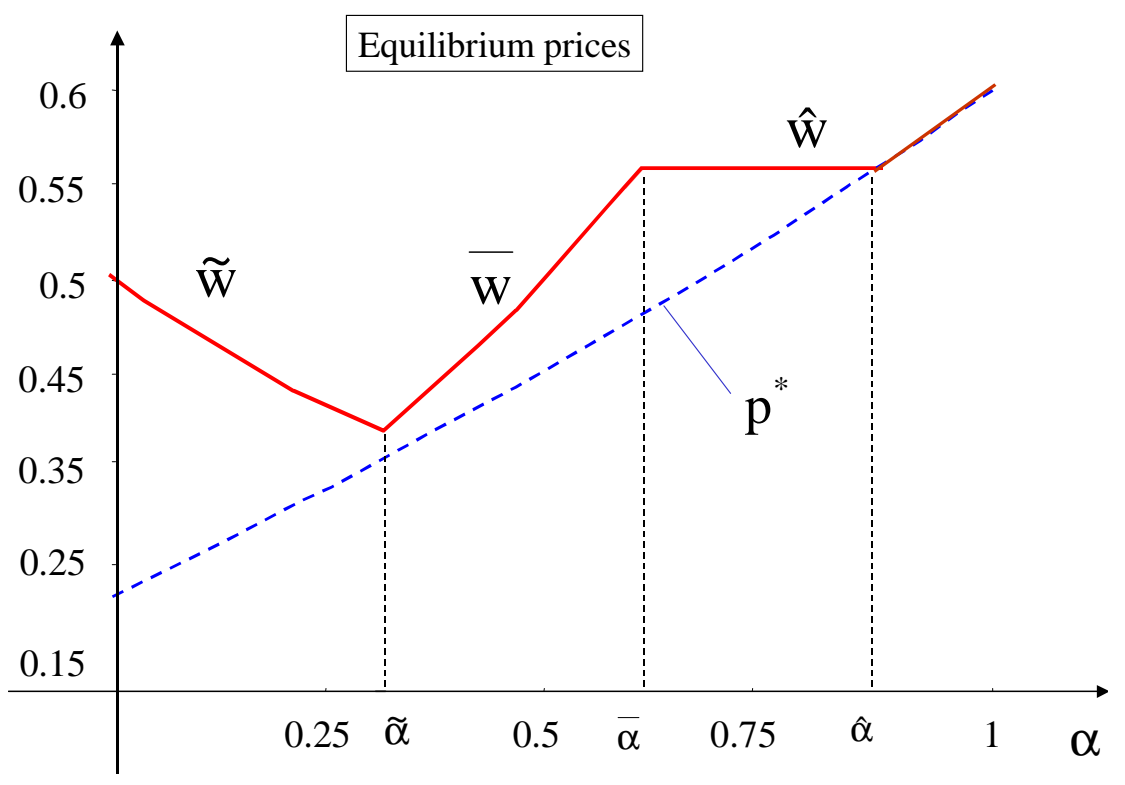

Figure 1

In the next sections we compare the price-floor equilibrium outcomes to the equilibrium outcomes with no restriction (section 5.2) and with $R P M$ contracts (section $5.3)$.

\subsection{Price-floor vs no-restriction equilibria}

We study the equilibrium outcomes when the law implements price-floor equilibria, i.e. for $\alpha \leq \widehat{\alpha}$.

Proposition 10 Under the $R B C$ law, equilibrium retail prices are strictly higher than in the no-restriction equilibrium for any $\alpha \leq \widehat{\alpha}$, and equal for $\alpha \geq \widehat{\alpha}$. A RBC law reduces welfare.

Proof : See Appendix A4.

From Remark 1, the RPM price $\widetilde{w}$ is higher than the no-restriction retail price $p^{*}$ for $\alpha \leq \widetilde{\alpha}$ (see Appendix A.3.1). Furthermore, $\bar{w}$ is also above the unconstrained 
price $p^{*}$. The intuition is simple. For a given retail price, the producers get higher margins when the retailers are constrained, because the retailers' status-quo profits are lower when they are constrained: This implies that, for the same retail price, the net transfer $\bar{t}$ is higher than $t^{*}$. Yet $\bar{w}$ is the price the retailers would choose without constraint and with a unit cost of $\bar{t}: \bar{w}=p^{e}(\bar{t})$, as $p^{*}$ is the price they would choose without constraint and with a unit cost of $t^{*}: p^{*}=p^{e}\left(t^{*}\right)$. As the retailers' equilibrium prices $p^{e}(t)$ increase with the unit cost $t, \bar{w} \geq p^{*}$. Note that for $\alpha=0$, producers have no power, the net transfers paid by the retailers are zero in both the constrained and no-restriction case, therefore $\bar{w}$ would thus be equal to $p^{*}$. Finally, $\widehat{w}$ is constant and above $p^{*}$ as long as $\alpha \leq \widehat{\alpha}$ since $p^{*}$ increases in $\alpha$ and $p^{*}=\widehat{w}$ for $\alpha=\widehat{\alpha}$. Note that the price-floor mechanism may lead to equilibrium retail prices above the monopoly price $1 / 2$.

The retail price increase induced by the $\mathrm{RBC}$ law is maximum either in $\alpha=0$ or in $\alpha=\bar{\alpha}$. When the law implements the RPM equilibrium, as $\widetilde{w}$ decreases in $\alpha$ while the no-restriction price increases in $\alpha$, the price rise is maximum for $\alpha=0$. Yet when the law implements limit price-floor equilibria, $\widetilde{\alpha} \leq \alpha \leq \bar{\alpha}$, the price rise strictly increases in $\alpha$, and there is another local maximum in $\bar{\alpha}$. When retail competition is low, especially if producers' competition is low too, the global maximum is in $\alpha=\bar{\alpha}$ : the $\mathrm{RBC}$ law induces then a stronger retail price increase than a RPM. ${ }^{22}$

Proposition 11 A price-floor internalizes intra-brand competition and reduces interbrand competition.

We have shown in Proposition 4 that a RPM internalizes downstream competition and dampens upstream competition. Under $R B C$ law this holds for $\alpha \leq \widetilde{\alpha}$. For $\alpha \geq \widetilde{\alpha}$, the corner solutions (either in price or in transfer) also saturate the retailers pricing constraint, thus suppressing retail competition. Besides, the corner price-floor strategy fosters some collusion between the producers: Each producer anticipates that his competitor will set higher prices in order to hinder his retailers from deviating in stage 3 , and this reduces upstream competition. The same pro-collusive mechanism holds for the limit transfer equilibrium.

Proposition 12 The law shifts the sharing of profits in favor of producers. Producers are better off under the RBC law than in the no-restriction case, whereas retailers' profits are higher under the law only when their bargaining power is high ( $\alpha$ low).

${ }^{22}$ This happens for $b \leq \bar{b}(a)$ where $\bar{b}$ decreases in $a$. 
First, the effect of the law on total industry profits is ambiguous. When $\alpha \leq \widetilde{\alpha}$, total industry profit is higher in the RPM equilibrium (also implemented through a price-floor) than in the no-restriction situation, as $p^{*} \leq \widetilde{w} \leq \frac{1}{2}$ where $1 / 2$ is the monopoly price that maximizes industry profits. However, for larger values of $\alpha$, the price-floor equilibria may reduce total industry profit: In the corner price-floor equilibria the equilibrium retail price may be too high $\left(\bar{w}>\frac{1}{2}\right.$ if $\left.\alpha>\frac{b}{1-a+b}\right)$ and the total industry profit smaller than in the no-restriction situation.

Second, when retailers' pricing strategies are constrained, producers manage to extract a greater share of joint profits: Retailers loose the follower advantage they had in the no-restriction situation. This positive effect on producers' share of total profit dominates the potential loss of total profit, and producers always benefit from a RBC law. In contrast, retailers may benefit from the law only if the joint profit's increase is very large, i.e. when they have a very strong bargaining power: When $\alpha$ is less than $\alpha^{d}$ (where $\alpha^{d}<\widetilde{\alpha}$ ), retailers manage to extract some of the total surprofit generated by the price-floor strategy. In that case, all the firms are better off with the price-floor strategy. However, when the producers' bargaining power increases, they become able to keep the whole surprofit at the upstream level, and retailers' profits are lower than in the no-restriction case. Finally, producers' profit under $R B C$ laws increase with their bargaining power $\alpha$, except for $\alpha \in[\bar{\alpha}, \widehat{\alpha}]$, where it is constant.

\subsection{Price-floor equilibria vs RPM equilibrium}

Here we compare the price-floor and the $R P M$ equilibrium outcomes.

Proposition 13 Retail prices are higher and welfare lower under RBC law than with RPM contracts.

Proof : see Appendixes A3 and A4

First, when the price-floor does not implement the $R P M$ equilibrium $(\alpha \geq \widetilde{\alpha})$, retail prices are higher in the corner price-floor equilibria than in the $R P M$ equilibrium: For $\alpha=\widetilde{\alpha}, \bar{w}=\widetilde{w}$, and $\bar{w}$ increases in $\alpha$ ( $\widehat{w}$ is constant) whereas $\widetilde{w}$ decreases in $\alpha$. The gap between a price-floor and a RPM widens when producers have more bargaining power. Second, we show in the Appendix that total welfare is inversely related to the retail prices. Therefore welfare is lower under the law than with $R P M$ contracts. We have shown in section 4.2 that a $R P M$ may enhance welfare, compared to the no-restriction case, when $\alpha$ is rather large: Yet in that case a price-floor no 
longer implements the $R P M$ equilibrium, it leads to higher prices that hurt welfare. Under the law, welfare is maximum when the retail price is minimum, i.e. for $\alpha=\widetilde{\alpha}$. In contrast, the welfare loss is the largest when the retail price increase is maximum, either in $\alpha=0$ or in $\alpha=\bar{\alpha}$.

Proposition 14 Producers' profit may be larger with a price-floor than with a RPM.

Proof : straightforward from Appendixes A2 and A3.

The proposition may seem counterintuitive since a $R P M$ is a stronger vertical restraint than a price-floor and therefore could appear as a more sophisticated tool bringing higher profits. This is not the case however, and the reason is that the total industry profit may be higher with a price-floor than with a RPM. For $\alpha=\widetilde{\alpha}$, $\bar{w}=\widetilde{w} \leq \frac{1}{2}$, and total industry profit is the same in the two cases. When $\alpha$ increases, on the one hand, producers' competition gradually drives the RPM price down: The industry profit decreases with $\alpha$. On the other hand, the corner price-floor $\bar{w}$ increases with $\alpha$ and as as long as $\bar{w}$ remains below $1 / 2$ (i.e. for $\alpha \leq \frac{b}{1-a+b}$ ), the total industry profit also increases with $\alpha$. For intermediary values of $\alpha$ total industry profit is thus higher with a price-floor than with a RPM. Besides, stage 2 negotiations lead to the same sharing of joint profit between the firms in the RPM equilibrium than in the corner price-floor equilibrium. Therefore producers' profit is higher with pricefloor than with $R P M$ at least for $\alpha \in\left[\widetilde{\alpha}, \operatorname{Min}\left(\frac{b}{1-a+b}, \bar{\alpha}\right)\right]$. For larger values of $\alpha$, the comparison becomes ambiguous: First, joint profit is not necessarily larger, and second, producers' share of profit decreases in the corner transfer equilibrium, as they reduce the transfers in order to maintain the stage 3 constraint binding, and receive thus a strictly lower share of profits than with a RPM.

\section{The effect of competition}

A comparative statics analysis on the substitution parameters $a$ and $b$ highlights some interesting properties.

Remark 2 In all equilibria, retail prices strictly decrease with a and $b$; The transfers increase in $b$ and decrease in $a$.

In all equilibria, retail prices decrease in $a$ and $b$. Intuitively, upstream as well as downstream competition lowers prices. The role of $a$ and $b$ on the net transfers 
is more contrasted. The net transfers decrease in $a$, which reflects the substitution between the producers: When $a$ goes to 1 , the net transfers go to zero irrespective of $\alpha$, as upstream competition drives producers' profits towards zero. Conversely, the transfers increase in $b$, the substitution between the retailers. The only exception is the corner transfer equilibrium, where $\widehat{t}$ is independent from $b$ by construction.

Furthermore, producers' profits decrease in $a$ and retailers' profits decrease in $b$ : $a$ and $b$ influence the balance of power between producers and retailers. A strong interbrand competition strengthens the retailers' position vis-à-vis the suppliers, thus increasing their equilibrium profits and reducing the producers'. In contrast, a strong intrabrand competition weakens the retailers and reduces their profits. In particular, a firm's status-quo profit is higher when it faces a more differentiated competitor: In our model, buyer power is affected by both the exogenous bargaining power $\alpha$ and the variations of the status-quo profits with competition.

We now turn to the influence of $a$ and $b$ on the existence of price-floor equilibria.

Remark 3 The threshold $\widehat{\alpha}$ strictly decreases with $b$.

The interval of bargaining power $\alpha$ for which price-floor equilibria exist shrinks when retail competition becomes tougher: If $b=0$, a price-floor equilibrium exists for $\alpha \leq 1$, whereas if $b=1$, there is no price-floor equilibrium when $\alpha>\frac{1}{2}$. The intuition is simple. For $\alpha>\widehat{\alpha}$, price-floor equilibria no longer exist because producers switch to the no-restriction equilibrium. Yet the no-restriction equilibrium transfers, and therefore producers' profits, are higher when downstream competition is tougher, thus producers switch to the no-restriction equilibrium earlier (i.e. for lower $\alpha$ ) when $b$ is higher. Note that by construction, $\widehat{\alpha}$ is independent of $a$.

Consider now the influence of $a$ and $b$ on the nature of price-floor equilibria.

Remark 4 The threshold $\widetilde{\alpha}$ decreases in a and increases in $b$.

As downstream competition reduces the no-restriction best response price of a retailer $p^{B R}\left(w_{A}, w_{B}\right)$, but increases the $R P M$ price, it is likely that if $b$ increases the price-floor will implement the RPM equilibrium for higher $\alpha$, therefore $\widetilde{\alpha}$ increases with $b$. When $b=0$, the price-floor never implements the RPM equilibrium $(\widetilde{\alpha}=0)^{23}$.

\footnotetext{
${ }^{23}$ Note that if $b=0$ and $a$ goes to 1 , the no-restriction price and both price-floors $\bar{w}$ and $\widehat{w}$ go to $\frac{1}{2}$. Retailers receive the monopoly profit for all $\alpha$. By contrast, a $R P M$ would go to zero when $\alpha$ goes to 1 , and all firms would get zero profits. This example highlights fundamental differences between the price-floor and the RPM.
} 
If $b>0, \widetilde{\alpha}$ decreases with $a$ : the no-restriction best response price of a retailer and the optimal RPM price-floor $\widetilde{w}$ decrease with $a$, but the latter is steeper than the former. In the price-floor equilibria, competition between producers over the pricefloor is fiercer than in the no-restriction case, where retailers' positive margins absorb some of the variations of wholesale prices, thus dampening upstream competition (cf. Rey and Stiglitz, 1995).

\section{$7 \quad$ Robustness and extensions}

\subsection{Two-Part tariff}

So far we have assumed that tariffs were linear, and that negotiations determined unit net transfers. We check here the robustness of our results to the introduction of two-part tariff contracts. ${ }^{24}$ We assume that stages 1 and 3 of the game are unchanged, but that the stage 2 negotiations now define, for each pair of producer $K$ and retailer $i$, a unit wholesale price $t_{K i}$ and a fixed fee $F_{K i}$, both positive. The total transfer $i$ pays $K$ for the quantity $q_{K i}$ is now $t_{K i} q_{K i}+F_{K i}$. All proofs are in Appendix A5.1

Lemma 15 In the no-restriction case with two-part tariffs, the equilibrium wholesale tariff is $\left(t_{K i}^{T P}=0, F_{K i}^{T P}=\frac{\alpha(1-a)(1-b)}{(1+a)(1+b)(2-b)^{2}}\right)$. The retail price is $p_{K i}^{T P}=\frac{1-b}{2-b}$.

Classically, two-part tariffs suppress double margin: the unit wholesale price is zero, so that each retailer, facing zero marginal cost, behaves as a vertically integrated retailer selling the two differentiated products. Retail prices are then independent of $\alpha$, and are equal to the equilibrium retail price for $\alpha=0$ with linear tariffs. Without restraint, retail prices are thus lower with two-part tariffs than with linear unit prices. Two-part tariffs internalize interbrand competition, but retail prices still account for intrabrand competition: the full monopoly profit is not achieved, as final prices are lower than the full collusion price (1/2). Note that two-part tariffs reduce total profits, unless competition is low at both levels and producers have a high bargaining power: the reduction of retail prices induced by these tariffs most often drives prices further away from the joint-profit maximizing price $1 / 2 .^{25}$

\footnotetext{
${ }^{24} \mathrm{~A}$ few recent econometric studies test for the prevalence of non-linear or linear pricing, see for instance Bonnet et al. (2004) and Villas-Boas (2004).

${ }^{25}$ Except for $\alpha \in\left[\frac{2 b(2-b)}{2-b^{2}-2 a(1-b)}, 1\right]$, see Appendix A.5.1.
} 
Consider now that the producers can use $R P M$ contracts or that the law allows them to impose a price-floor. Equilibria in these two cases are very similar.

Lemma 16 With two-part tariffs, with a RPM or a price-floor, there exists a continuum of equilibria where retail prices are $w^{\circ}(t)=\frac{1}{2}\left(1-t \frac{b+\alpha(a-b)}{\alpha(1-a)}\right)$, with $0 \leq t \leq t_{R P M}=$ $\frac{\alpha(1-a)}{b+\alpha(2-a-b)}$ for $R P M$ contracts, $0 \leq t \leq t_{P F}=\frac{\alpha b(1-a)}{b(2-b)+\alpha(2-b(2+a-b))}$ for price-floors, and $t_{P F} \leq t_{R P M}$.

In both cases, there exists a continuum of equilibria. For any $\alpha$, there exists an equilibrium where competition is neutralized at both level: if $t=0$ the firms achieve the monopoly price $p^{M}=1 / 2$. Given $\alpha$, among the continuum of equilibria, the retail price $w^{\circ}(t)$ decreases in the unit wholesale price $t$, and so does the joint profit. Besides, all equilibria are not equivalent in terms of profit sharing: producers' profit increases and retailers' profit decreases in $t$. There are two reasons for this. First, the unit price $t$ positively affects the producers' status-quo profits: if $t_{K j}$, the variable part of the transfer, is zero, in case of a failure in negotiation between $K$ and $i$, producer $K$ does not benefit from the increase in demand for his product at the other retailer's shop, whereas the retailer benefits from the increase of demand for the other brand she sells: this tends to reduce the producer's status-quo profit. Increasing $t$ therefore shifts the sharing in favour of the producers. Second, in equilibrium the producers choose $R P M$ prices that do not necessarily maximize joint profit, in order to increase their status-quo profits and their share of total profit. It is a consequence of the direct effect of the $R P M$ price on the firms' status-quo profits: negative for the producers, as it decreases their status-quo demand, but locally positive for the retailers. Note that this result would hold with an upstream monopoly.

The range of equilibria sustainable with RPM includes the equilibria sustainable with price-floors. With $R P M$, the set of equilibrium prices is the interval $\left[w\left(t_{R P M}\right), 1 / 2\right]$. Yet price-floors do not implement all $R P M$ equilibria, as the lowest prices are not binding and retailers deviate in stage 3 : Therefore with price-floors, given $\alpha$, the set of equilibrium prices is the interval $\left[w\left(t_{P F}\right), 1 / 2\right]$ where $t_{P F} \leq t_{R P M}$, $w\left(t_{R P M}\right) \leq w\left(t_{P F}\right)$ and $R P M$ allows for equilibria with lower prices than price-floors.

In both cases, the set of equilibrium retail prices shrinks when producers' bargaining power increases. Consider the $R P M$ case. If the retailers have all bargaining power $(\alpha \rightarrow 0)$, all prices from 0 to the monopoly price are sustainable in equilibrium, but when $\alpha$ goes to 1, producers do not impose a $R P M$ price lower than $\frac{1-a}{2-a}$, the price that would be chosen by vertically integrated producers. Similarly, with price-floors, 
the lowest equilibrium price-floor for $\alpha=0$ is $w_{P F}^{\circ}(\alpha=0)=\frac{1-b}{2-b}$, the same than with linear tariffs and no vertical restraint; for $\alpha=1$, it is higher: $w_{P F}^{\circ}(\alpha=1)=\frac{1-a b}{2-a b}$.

Finally, in any price-floor equilibrium, retail prices are higher than in the norestriction equilibrium $\left(w_{P F} \geq \frac{1-b}{2-b}\right)$. As a consequence, joint profits are also higher. Note that producers' profit is always higher with price-floor than without restriction.

Proposition 17 Under $R B C$ law, when producers and retailers bargain over two-part tariffs, equilibrium retail prices are higher than without restraint. The price rise and welfare loss are worse than with RPM contracts.

The price-raising effect of $R B C$ laws is thus robust to the introduction of two-part tariffs. Note that under the law, with two-part tariffs, the highest welfare is attained for $\alpha=0$ where the minimum retail price is attained. This contrasts with the linear tariff case where the welfare was minimum for $\alpha=0$. Besides, as with linear tariffs, producers are better off with price-floors, which relax completely downstream competition and partially upstream competition. However, under $R B C$ laws, producers are better off with linear transfers than with two-part tariffs. Moreover, the two-part tariff transfers analysis has the drawback to raise multiple equilibria ${ }^{26}$.

\subsection{Individual price-floors}

Both the assumptions that unit prices set in stage 1 are non discriminatory and that net transfers negotiated in stage 2 cannot enter in the legal definition of the pricefloors imply that producers impose industrywide price-floors. Here, we relax this assumption and discuss the issue of possible discriminatory or individual price-floors.

Assume that in stage 2, producers and retailers bargain over two kinds of rebates, one included in the definition of the price-floor and the other not. Price-floors are now negotiated by pair. Let $t_{K i}-f_{K i}$ denote the total net transfer agreed between producer $K$ and retailer $i$, where $t_{K i}$ is the legal price-floor. Under the law, in stage 3 , retailers must set prices above $t_{K i}$. We show that, in equilibrium, the legal constraint is never binding: Since the price-floor is now individual instead of industrywide, each pair has a unilateral incentive to set a lower price-floor than the other pairs. Finally, the optimal price-floor is always too low and retailers always set higher prices.

\footnotetext{
${ }^{26}$ Note that, given $a, b$ and $\alpha$, the Pareto criterion would select, among the continuum, the equilibrium which gives the highest profit to the producers, i.e. the maximum variable part $t=t_{P F}$ and the minimum retail price $w\left(t_{P F}\right)$.
} 
Proposition 18 There is no price-floor equilibrium when producers and retailers bargain over the price-floor level.

Proof: see Appendix A5.2.

This result suggests a reform that would reduce the anticompetitive effect of RBC laws. Without giving away the very principle of the law, changing the definition of the price threshold would be sufficient to eliminate the price-floor mechanism, and thus most of the price effect of the law. The example of Spain gives a good illustration. The Spanish RBC law is very similar to the French law since the deferred rebates cannot be included in the price-threshold. However, the law does not require the general terms of sales to be published by the producers. Thus producers and retailers can bargain over the unit price as well as the deferred rebates. Inflationary effects have proved to be rather limited. ${ }^{27}$

\subsection{Ex-post observability of the bargaining outcome}

We discuss here the assumption of no ex-post observability (EPO) of the negotiation. As we intend to focus on the changes induced in the retailers' strategies, let us consider the simple case of an upstream monopoly $(a=0)$. After stage 2 , the issue of the negotiations are made public, so that each retailer knows which products are sold by her competitors and at which cost. This involves a reduction of the producer's status-quo profit: in case of a failure in one negotiation, the other retailer is aware of being a monopoly in stage 3, and increases her price, which reduces demand and the producer's status-quo profit. Everything happens as if ex-post observability of the bargaining outcomes increased retailers' buyer power. Therefore, with no restriction, EPO leads to lower equilibrium net transfers and retail prices. In contrast, the price-floor is higher with EPO: As the issue of negotiations is less favorable to the producer, his margin is lower and he thus has an incentive to increase the retail price. Furthermore, the price-floor strategy is chosen by the producer for a wider interval of $\alpha$ than without EPO. The price-raising effect of the price-floor mechanism is thus even worse with EPO (see Appendix A5.3 for the proofs).

\footnotetext{
${ }^{27}$ See Canivet, p 68.
} 


\section{Conclusion}

This article highlights the impact of a price-floor restraint in a vertical structure with imperfect upstream and downstream competition and negotiation over contracts. The main result is that price-floors suppress downstream competition but also dampen producers' competition. Moreover, as a price-floor reduces retailers' pricing latitude, it pares buyer power and enables producers to get a larger share of joint profits. Thus, producers always benefit from price-floors. When their bargaining power is high enough, retailers may also benefit from a price-floor. Furthermore, the comparison of price-floor and RPM shows that if both restraints have similar anticompetitive effects, a price-floor may be more profitable for producers, leads to higher retail prices and is worse for welfare than a RPM. All these results hold with either linear or two-part tariff contracts. This article also shows that, with linear tariffs, retailers' buyer power is a key factor to enforce a price-floor mechanism: If producers have most of the bargaining power, a price-floor becomes useless as it is not binding.

Finally, our results contribute to the debate on the price effects of RBC laws, which exists in almost all countries that have enacted such laws. The model shows how, paradoxically, RBC laws provide roundabout means for producers to impose pricefloors, a vertical restraint that is banned per se in the US ${ }^{28}$ and EU competition laws. We thus provide a theoretical explanation for some price-raising effects of RBC laws where no predatory pricing is involved, and which is independent from loss-leading practices. Moreover, we prove that this price effect relies only on the definition of the price threshold adopted in RBC laws. This article shows how integrating backroom margins in this threshold would be sufficient to prevent most of the inflationary effects of the law. This has been the basis of the RBC law reform adopted in 2006 in France (see Canivet, 2004).

\section{References}

Allain, M.L. and Chambolle C. (2005), "Loss-Leaders Banning Laws as Vertical Restraints", Journal of Agricultural and Food Industrial Organization, 3, Berkeley Electronic Press, http://www.bepress.com/jafio.

\footnotetext{
${ }^{28}$ Note that since the Leegin case in june 2007, the US Supreme Court has stated that courts should decide further RPM cases under a rule of reason rather than a per se rule (Leegin Creative Leather Products, Inc. vs. PSKS Inc., 551 US 2007).
} 
Anderson, R. and Johnson R. (1999), "Antitrust and Sales-Below-Cost Laws: the Case of Retail Gasoline, Review of Industrial Organization 189, 14.

Binmore, Rubinstein and Wolinsky (1986), "The Nash Bargaining Solution in Economic Modelling", RAND Journal of Economics, 17, 176-188.

Bonnet, C. Dubois, P. and Simioni M. (2004), "Two-part tariffs versus linear pricing between manufacturers and retailers : empirical tests on differentiated products markets", Working Paper.

Calvani, T. (1999), "Predatory pricing and State below-cost sales statutes in the United States : an analysis", report for Industry Canada, Competition Bureau.

Canivet (2004) "Rapport du groupe d'experts constitué sur les rapports entre industrie et commerce", Cour de Cassation.

Caprice, S. (2006) "Multilateral Vertical Contracting with an Alternative Supply: The Welfare effects of a Ban on Price Discrimination", Review of Industrial Organization, 28, 63-80.

Collins, A, S. Burt and Oustapassidis K. (2001), "Below-cost legislation and retail conduct: evidence from the Republic of Ireland", British Food Journal, 103 (9), 607622 .

Crémer, J. and Riordan, M.H. (1987), "On governing Multilateral Transactions with Bilateral Contracts", RAND Journal of Economics, 18, 436-451.

de Fontenay, C. and J. Gans (2005), "Vertical Integration in the Presence of Upstream Competition", RAND Journal of Economics, 36 (3), 544-572.

Dobson, P. and Waterson M. (1996), "Product range and interfirm competition", Journal of Economics and Management Strategy 5 (3), 317-341.

European Commission (1999), Buyer Power and Its Impact on Competition in the Food Retail Distribution Sector of the European Union: Final Report.

Inderst, R. and Mazzarotto N. (2006), "Buyer Power Sources, Consequences, and Policy Responses," Working Paper, October.

Johnson, R. (1999), "The Impact of Sales-Below-Cost Laws on the U.S. Retail Gasoline Market", report prepared for Industry Canada Competition Bureau, 1999.

McAfee, P. Schwartz, M. (1994), "Opportunism in Multilateral Vertical Contracting: Non Discrimination, Exclusivity and Uniformity", The American Economic Review, 84 (1), 210-230.

Motta, M. (2004), "Competition Policy Theory and Practice". Cambridge: Cambridge University Press.

O'Brien, D. and Shaffer, G. (1992) "Vertical Control with Bilateral Contracts", 
RAND Journal of Economics, 23, 3, 299-308.

OECD (1999), "Buying Power and Multiproduct retailers", series of roundtables on Competition Policy DAF/CLP, 21.

OECD (2006), "Resale-Below-Cost Laws and Regulations", DAF/CLP.

Rey, P. and Stiglitz, J. (1995), "The Role of Exclusive Territories in Producers' Competition", Rand Journal of Economics, 26,(3), 431-51

Rey, P. and Tirole J. (1986), "The logic of vertical restraints", American Economic Review 76, 921-939.

Rey, P. and Vergé, T. (2004 i), "Resale Price Maintenance and Horizontal Cartel", Working Paper.

Rey, P. and Vergé, T. (2004 ii), "Bilateral Control with Vertical Contracts", RAND Journal of Economics, 35, 4, 728-746.

Segal, I. (1999), "Contracting with externalities", The Quarterly Journal of Economics, 114, 2, 337-388.

Shaffer, G. (1991), "Slotting allowances and resale price maintenance: a comparison of facilitating practices", RAND Journal of Economics, 22, 120-135.

Skidmore, M., Peltier, J. and Alm, J. (2005), "Do State Motor Fuel Sales-BelowCost laws lower prices?", Journal of Urban Economics, 57, 189-211.

Tirole, J. (1988), "The Theory of Industrial Organization", MIT Press.

Villas-Boas, S.B. (2004), "Vertical contracts between manufacturers and retailers: inference with limited data", forthcoming in Review of Economic Studies.

Walsh, P.P. and Whelan, C. (1999), "Loss-Leading and Price Intervention in Multiproduct Retailing: Welfare Outcomes in a Second-Best World", International Review of Law and Economics, 19, 333-347.

\section{A Appendix ${ }^{29}$}

\section{A.1 No restriction on resale prices}

We solve the game by backward induction. We look only for symmetric equilibria where the four goods are sold.

\footnotetext{
${ }^{29} \mathrm{~A}$ more detailed version of the proofs is available in Allain and Chambolle (2007), Anticompetitive Effects of Resale Below Cost Laws, CREST Working Paper.
} 


\section{A.1.1 Stage 3}

Consider the stage 3 subgame, where net transfers $t_{K i}, K \in\{A, B\}, i \in\{1,2\}$, and both wholesale prices $w_{A}$ and $w_{B}$ are fixed. Retailer $i$ knows the public values of the wholesale prices $w_{A}$ and $w_{B}$ set by producers in stage 1 and the issue of stage 2 , that is the true values of the unit transfers $t_{A i}$ and $t_{B i}$ if her negotiations with both suppliers have succeeded. However, she ignores the issue of the negotiations of her competitor $j$ with both suppliers. Let us denote $p_{K j}^{a}$ the value of the retail price for product $K j$ anticipated by retailer $i$ in stage 2 , and $t_{K j}^{a}$ her anticipation of the transfer agreed between her competitor $j$ and supplier $K$.

In stage 3 , retailer $i$ maximizes her concave profit:

$$
\underset{p_{A i}, p_{B i}}{\operatorname{Max} \Pi_{i}}=\left(p_{A i}-t_{A i}\right) D_{A i}\left(p_{A i}, p_{A j}^{a}, p_{B i}, p_{B j}^{a}\right)+\left(p_{B i}-t_{B i}\right) D_{B i}\left(p_{A i}, p_{A j}^{a}, p_{B i}, p_{B j}^{a}\right)
$$

The sufficient first-order conditions determine the best responses of the retailers: $p_{K i}^{B R}\left(t_{K i}, t_{L i}, p_{K j}^{a}, p_{L j}^{a}\right)=\frac{1+t_{K i}-b\left(1-p_{K j}^{a}\right)}{2}$, for $\{K, L\}=\{A, B\},\{i, j\}=\{1,2\} .{ }^{30}$ The intersection of the best responses, denoted $p_{K i}^{e}\left(t_{K i}, t_{K j}, t_{L i}, t_{L j}\right)$, gives the subgame equilibrium. It increases in $t_{K i}$ and $t_{K j}$ and is independent from $t_{L i}$ and $t_{L j}$.

\section{A.1.2 Stage 2}

The stage 2 of the game is the Nash-bargaining over the net transfers. The Nash program of the negotiation between producer $K$ and retailer $i$ is as follows:

$$
\underset{t_{K i}}{\operatorname{Max}}\left(\Pi_{K}-\Pi_{K}^{3}\right)^{\alpha}\left(\Pi_{i}-\Pi_{i}^{3}\right)^{1-\alpha}
$$

where $\Pi_{K}\left(\right.$ resp. $\left.\Pi_{i}\right)$ is the profit of producer $K$ (resp. retailer $i$ ) and $\Pi_{K}^{3}$ (resp. $\Pi_{i}^{3}$ ) is the status-quo profit earned by producer $K$ (resp. retailer $i$ ) if the negotiation breaks, i.e. if producer $K$ only deals with retailer $j$ (resp. retailer $i$ only deals with producer $L$ ), all other negotiations being successful. As they have passive beliefs, producer $K$ and retailer $i$ keep constant anticipations over the other pairs' negotiations outcome while negotiating in stage 2 . In equilibrium, these anticipations will be the equilibrium

\footnotetext{
${ }^{30}$ Note that $p_{K i}^{B R}$ depends only on the anticipated final price of the same brand sold by the other retailer, $p_{K j}^{a}$ : all the effect of interbrand competition is absorbed by the price $p_{L i}^{B R}$, set simultaneously by retailer $i$. This stems from the linearity of demand and the assumption $c=a . b$.
} 
outcomes. More precisely, we have:

$$
\begin{aligned}
\Pi_{K}= & t_{K i} D_{K i}\left(p_{K i}^{B R}\left(T^{a}\right), p_{K j}^{a}, p_{L i}^{B R}\left(T^{a}\right), p_{L j}^{a}\right)+ \\
& t_{K j} D_{K j}\left(p_{K j}^{a}, p_{K i}^{B R}\left(T^{a}\right), p_{L j}^{a}, p_{L i}^{B R}\left(T^{a}\right)\right) \\
\Pi_{i}= & \left(p_{K i}-t_{K i}\right) D_{K i}\left(p_{K i}^{B R}\left(T^{a}\right), p_{K j}^{a}, p_{L i}^{B R}\left(T^{a}\right), p_{L j}^{a}\right)+ \\
& \left(p_{L i}-t_{L i}\right) D_{L i}\left(p_{L i}^{B R}\left(T^{a}\right), p_{L j}^{a}, p_{K i}^{B R}\left(T^{a}\right), p_{K j}^{a}\right)
\end{aligned}
$$

where $T^{a}=\left(t_{K i}, t_{L i}, p_{K j}^{a}, p_{L j}^{a}\right)$.

To define the status-quo profits, assume that negotiation between producer $A$ and retailer 1 breaks. As the outcome of the negotiations is not observable ex-post, i.e between stages 2 and 3 , firms $B$ and 2 ignore this failure and behave according to their anticipations. Therefore while negotiating, firms 1 and $A$ anticipate that the negotiation between producer $B$ and retailer 2 is not affected and will lead to the equilibrium value $t_{B 2}^{*}$. Furthermore, the "schizophrenia of the negotiator" assumption implies that firms 1 and $A$ anticipate that their own negotiations with their other partners will not be affected and will lead to the equilibrium transfers $t_{A 2}^{*}$ and $t_{B 1}^{*}$, and that, as retailer 2 will have no information about the failure in negotiation, he will set the equilibrium prices $p_{A 2}^{a}=p_{A 2}^{*}$ and $p_{B 2}^{a}=p_{B 2}^{*}$ in stage 3 . However, firms 1 and $A$ also anticipate that, at the beginning of stage 3 , retailer 1 will be aware of the absence of product $A$ on her shelves, and that she will thus set the optimal price $p_{B 1}^{3}$ anticipating the real final demand when good $A 1$ is not distributed ${ }^{31}$, denoted $D^{3}$ :

$$
\begin{aligned}
& D_{B 1}^{3}\left(p_{A 2}, p_{B 1}, p_{B 2}\right)=\frac{1-b-p_{B 1}+b p_{B 2}}{1-b^{2}} \\
& D_{A 2}^{3}\left(p_{A 2}, p_{B 1}, p_{B 2}\right)=\frac{1-a-p_{A 2}+a p_{B 2}}{1-a^{2}}
\end{aligned}
$$

The optimal price for good $B 1$, set by retailer 1 in stage 3 , would thus be $p_{B 1}^{3}=$ $\frac{1-b\left(1-p_{B 2}^{a}\right)+t_{B 1}^{a}}{2}$. Note that $p_{K i}^{3}=p_{B 1}^{B R}$ : given the prices chosen by retailer $j$, the optimal price for product $K i$ is the same whether $i$ sells $L$ or not. This property holds for any linear demand function with symmetric cross-price derivatives. ${ }^{32}$ A change in

\footnotetext{
${ }^{31}$ In case of a failure in the bargaining between $\mathrm{A}$ and 1 , the consumers are aware that only three goods are available on the market to purchase, and therefore the demand for $A 1$ is divided between the three other goods. We determine the inverse demand for the three other goods by setting $q_{A 1}=0$ and invert them in order to derive the demands in that case.

${ }^{32}$ This property also holds for general demand functions if cross-price derivatives are symmetric and $\varepsilon_{A A}^{3}=\varepsilon_{A A}+\varepsilon_{A B}$ where $\varepsilon_{A A}^{3}$ is the direct-price elasticity of the demand for product $\mathrm{A}$ when only $A$ is sold, and $\varepsilon_{A A}$ and $\varepsilon_{A B}$ respectively the direct-price and cross-price elasticities of the demand when both products are sold.
} 
the demand function could raise a difference between $p_{B 1}^{3}$ and $p_{B 1}^{B R}$ but this would not change qualitatively our results. The status-quo profits anticipated by the negotiating firms are finally:

$$
\begin{aligned}
\Pi_{A}^{3} & =t_{A 2}^{a} D_{A 2}^{3}\left(p_{B 1}^{3}, p_{A 2}^{a}, p_{B 2}^{a}\right) \\
\Pi_{1}^{3} & =\left(p_{B 1}^{3}-t_{B 1}^{a}\right) D_{B 1}^{3}\left(p_{B 1}^{3}, p_{A 2}^{a}, p_{B 2}^{a}\right)
\end{aligned}
$$

The subgame equilibrium outcome of the negotiations is given by the resolution of the four Nash programs under the condition that the anticipated retail prices are the stage 3 subgame equilibrium prices $p_{K i}^{a}=p_{K i}^{e}\left(t_{K i}, t_{L i}, t_{K j}, t_{L j}\right)$. There exists a unique symmetric solution, irrespective of the wholesale prices:

$$
t_{K i}=t^{*}=\frac{2 \alpha(1-a)}{4-2 a \alpha-b(2-\alpha)}
$$

\section{A.1.3 Stage 1}

There exists a continuum of equilibria : In stage 1, any pair of wholesale prices $\left(w_{K}, w_{L}\right)$ may be chosen in equilibrium as long as the rebates negotiated in stage 2 lead to the net transfers $t^{*}$. These transfers increase in $\alpha$ and in $b$, and decrease in $a$.

Symmetric equilibrium retail prices are then (for the four goods):

$$
p^{*}=\frac{2(1-b)+\alpha(1-2 a+b)}{4-2 a \alpha-(2-\alpha) b}
$$

This retail price increase in $\alpha$ and decrease in $a$ and $b$.

Producers' and retailers' profits are:

$$
\begin{aligned}
\Pi_{K}^{*} & =\frac{4 \alpha(1-a)(2-\alpha)}{(1+a)(1+b)(4-2 a \alpha-(2-\alpha) b)^{2}} \\
\Pi_{i}^{*} & =\frac{2(1-b)(2-\alpha)^{2}}{(1+a)(1+b)(4-2 a \alpha-(2-\alpha) b)^{2}}
\end{aligned}
$$

$\Pi_{i}^{*}$ decreases in $\alpha$ and in $b$. $\Pi_{K}^{*}$ decreases in $a$. Furthermore, $\Pi_{K}^{*}$ is not always monotonous in $\alpha$ : if $a$ is large enough relatively to $b(b \leq 2 a), \Pi_{K}^{*}$ increases in $\alpha$, but otherwise $\Pi_{K}^{*}$ increases in $\alpha$ for small values of $\alpha\left(\alpha \leq \frac{4-2 b}{4-2 a-b}\right)$ and decreases after. ${ }^{33}$ Finally, the total profit of the industry is not always monotonous in $\alpha$. If $a$ and $b$ are large $(2(1-a) \leq b \leq 2 a)$ total profit increases in $\alpha$. Otherwise total profit increases in $\alpha$ for $\alpha \leq \frac{2 b}{2-2 a+b}$ and decreases after this threshold.

\footnotetext{
${ }^{33}$ That producers' profits may decrease in $\alpha$ is a consequence of the assumption that producers behave here as schizophrenic negotiators, and has no consequence on the main results. This effect is irrespective of upstream competition, and the following example gives the main insight. Consider a monopolist producer with $\alpha=1$. Let $\left(\overline{t_{1}}, \overline{t_{2}}\right)$ be the net transfers that would maximize the producer's profit.Assume that the producer sets the net transfer $\overline{t_{2}}$ with retailer 2 . When he bargains with retailer 1 over $t_{1}$, he considers that $\overline{t_{2}}$ is fixed. Increasing $t_{1}$ does not change his status-quo profit but
} 


\section{A.1.4 Discussion: robustness of the result to changes in the demand func- tion}

The coexistence of four different products (resulting from two sources of differentiation, intra- and inter-brands) makes the solving in the general case tedious (see for instance a discussion in Shaffer, 1991, with only two products). However, we claim that proposition 2 would hold under fairly standard assumptions. We provide some intuitions.

First, each retail price $p_{K i}^{B R}$ increases with the four net transfers $t_{K j}$ under fairly standard assumptions : by totally differentiating the stage 3 retailers' first-order conditions, one can determine $\frac{\partial p_{K i}^{B R}}{\partial t_{K i}}$ and $\frac{\partial p_{K i}^{B R}}{\partial t_{L i}}$. For instance

$$
\frac{\partial p_{A 1}^{B R}}{\partial t_{A 1}}=\frac{\frac{\partial^{2} \Pi_{1}}{\partial p_{B 1}^{2}} \frac{\partial D_{A 1}}{\partial p_{A 1}}-\frac{\partial^{2} \Pi_{1}}{\partial p_{A 1} \partial p_{B 1}} \frac{\partial D_{A 1}}{\partial p_{B 1}}}{\frac{\partial^{2} \prod_{1}}{\partial p_{A 1}^{2}} \frac{\partial^{2} \Pi_{1}}{\partial p_{B 1}^{2}}-\left(\frac{\partial^{2} \Pi_{1}}{\partial p_{A 1} \partial p_{B 1}}\right)^{2}}
$$

where the denominator of (5) is positive if the retailer's profit function is concave. Assuming the positivity of the numerator is then sufficient to ensure that the final price $p_{A 1}^{B R}$ increases in $t_{A 1}$.

Each net transfer is also increasing with the producer's bargaining power $\alpha$ for a broad range of demand functions. The negotiation between $K$ and $i$ leads to the net transfers maximizing the following Nash condition:

$$
\underset{t_{K i}}{\operatorname{Max}}\left(\Pi_{K}-\Pi_{K}^{3}\right)^{\alpha}\left(\Pi_{i}-\Pi_{i}^{3}\right)^{1-\alpha}
$$

Assuming the concavity of the Nash condition, the sufficient first-order condition is as follows:

$$
C P O\left(t_{K i}\right)=\alpha \frac{\partial\left(\Pi_{K}-\Pi_{K}^{3}\right)}{\partial t_{K i}}\left(\Pi_{i}-\Pi_{i}^{3}\right)+(1-\alpha)\left(\Pi_{K}-\Pi_{K}^{3}\right) \frac{\partial\left(\Pi_{i}-\Pi_{i}^{3}\right)}{\partial t_{K i}}=0
$$

where $\frac{\partial C P O}{\partial t_{K i}} \leq 0$ by concavity. We have:

brings about three anticipated effects: (i) an increase of his margin on product 1 (raising his profit), (ii) an increase of the retail price of product 1 leading to a decrease in demand (reducing his profit), and (iii) an increase in the demand for his product at the other retailer's (raising his profit). If $\overline{t_{2}}$ is fixed, the third effect partially compensates for the second, the compensation being more efficient when retailers' competition increases ( $b$ increases), and the producer increases $t_{1}$ above $\overline{t_{1}}$ to raise his profit. As he simultaneously does the same with the other retailer, and a joint increase of both net transfers suppresses the third effect of demand substitution: The global effect on the producer's profit is negative. 


$$
\frac{\partial t_{K i}}{\partial \alpha}=-\frac{\frac{\partial C P O}{\partial \alpha}}{\frac{\partial C P O}{\partial t_{K i}}}
$$

A sufficient condition for each net transfer to increase with the producer's bargaining power $\alpha$ is that given the three other net transfers, in the neighborhood of the equilibrium net transfer, the additional profit gained by a producer if his negotiation with a retailer succeeds (e.g. $\Pi_{K}-\Pi_{K}^{3}$ ) increases in the net transfer $t_{K i}$, whereas the additional profit for the retailer decreases in this net transfer. In that case, $\frac{\partial C P O}{\partial \alpha}=\frac{\partial\left(\Pi_{K}-\Pi_{K}^{3}\right)}{\partial t_{K i}}\left(\Pi_{i}-\Pi_{i}^{3}\right)-\left(\Pi_{K}-\Pi_{K}^{3}\right) \frac{\partial\left(\Pi_{i}-\Pi_{i}^{3}\right)}{\partial t_{K i}} \geq 0$, thus $\frac{\partial t_{K i}}{\partial \alpha}>0$.

Finally, as retail prices increase in the net transfers, and as long as direct effects dominate indirect effects, Proposition 2 will hold with a broad range of standard demand functions.

\section{A.2 The RPM equilibrium}

If producers impose RPM contracts, the retailers have to set prices $p_{K i}=w_{K}$ in stage 3. In stage 2 , the status-quo profits are slightly different. Consider the negotiation between $A$ and 1 . In case of a failure, the two negotiators anticipate now that the price of product $B 1$ set in stage 3 will be constrained by the RPM: $p_{B 1}=w_{B}$. The status-quo profits are thus:

$$
\begin{aligned}
\Pi_{A}^{3} & =\frac{t_{A 2}\left(1-a-w_{A}+a w_{B}\right)}{\left(1-a^{2}\right)} \\
\Pi_{1}^{3} & =\frac{\left(1-w_{B}\right)\left(w_{B}-t_{B 1}\right)}{(1+b)}
\end{aligned}
$$

The resolution of the four Nash conditions gives the following optimal net transfers:

$$
\widetilde{t}_{K i}\left(w_{K}, w_{L}\right)=\alpha \frac{\left(1-a^{2} \alpha-(1-\alpha) b\right) w_{K}-a(1-\alpha)(1-b) w_{L}}{(1-(1-\alpha) b)^{2}-a^{2} \alpha^{2}}
$$

Note that, given $w_{L}, \frac{\partial \widetilde{t}_{K i}}{\partial w_{K}} \geq 0$ : producer $K^{\prime} s$ margin now increases in $w_{K}$.

In stage 1, producer $K$ sets the wholesale price that maximizes his profit:

$$
\underset{w_{K}}{\operatorname{Max}} \widetilde{t}_{K i}\left(w_{K}, w_{L}\right) \cdot\left(D_{K 1}\left(w_{K}, w_{L}\right)+D_{K 2}\left(w_{K}, w_{L}\right)\right)
$$

The optimal wholesale prices are then:

$$
w_{K}=\widetilde{w}=\frac{1-a^{2} \alpha-b+\alpha b}{2+a \alpha-a^{2} \alpha-2(1-\alpha) b}
$$


The net transfers negotiated in stage 2 are:

$$
\widetilde{t}_{K i}=\widetilde{t}=\frac{\alpha(1-a)\left(1-a^{2} \alpha-(1-\alpha) b\right)}{(\alpha((1-a) a+2 b)+2(1-b))(1-b+\alpha(b-a))}
$$

The producers' profits are:

$$
\widetilde{\Pi}_{K}=\frac{2 \alpha(1-a)(1+a \alpha-(1-\alpha) b)\left(1-a^{2} \alpha-(1-\alpha) b\right)}{(1+a)(1+b)[2+a \alpha(1-a)-2(1-\alpha) b]^{2}(1-b+\alpha(b-a))}
$$

The comparison of the retail prices $\widetilde{w}$ to the equilibrium prices in the unconstrained case $p^{*}$ is straightforward: $\widetilde{w} \geq p^{*} \Leftrightarrow \alpha \leq \alpha_{I}$ where

$$
\alpha_{I}=\frac{2\left(1+a^{2}\right)-b-3 b^{2}-\sqrt{4 a^{2}+8 a(1-b)^{2} b+\left(2-b+b^{2}\right)^{2}+4 a^{2}\left(2-7 b+3 b^{2}\right)}}{6 a^{2}-2 a(1-b)-2 b(2+b)} .
$$

\section{A.3 Price-floor equilibria}

\section{A.3.1 The price-floor implements the $R P M$ equilibrium}

We determine the conditions under which the price-floor is a sufficient tool to implement the RPM equilibrium outcomes, by checking that no deviation occurs.

No deviation by a retailer in stage 3 Assume that the producers have set the price-floor $\widetilde{w}$ in stage 1 , and that the stage 2 negotiations have determined the $R P M$ equilibrium transfers $\widetilde{t}$. In stage 3 , if retailer $i$ anticipates that her rival sets price $p_{K j}=\widetilde{w}$, she can still set a price $p_{K i}$ above the price-floor $\widetilde{w}$. Appendix A1 gives the best response prices of retailer $i: p_{K i}^{B R}(\widetilde{t}, \widetilde{w})=\frac{1+\widetilde{t}-b(1-\widetilde{w})}{2}$. No deviation occurs in stage 3 if $p_{K i}^{B R}(\widetilde{t}, \widetilde{w}) \leq \widetilde{w}$, or:

$$
\widetilde{t} \leq \widetilde{w}(2-b)-1+b
$$

This condition is monotonous in $\alpha$, therefore this defines a threshold $\widetilde{\alpha}$ such that retail prices will indeed be constrained by a price-floor if and only if:

$$
\alpha \leq \widetilde{\alpha}=\frac{1+a^{2}-2 b^{2}-\sqrt{1+2 a^{2}+a^{4}-8 a^{2} b+4 a^{2} b^{2}}}{2\left(2 a^{2}-b-b^{2}\right)}
$$

Note that $\widetilde{\alpha} \leq \alpha_{I}$. 
No deviation in stage 2 Assume that the producers have set the price-floor $\widetilde{w}$ in stage 1 , and that $\alpha \leq \widetilde{\alpha}$. Consider the negotiation between producer $A$ and retailer 1 in stage 2 given that the three other pairs negotiate the transfer $\widetilde{t}$.

First, if the negotiation fails, the downstream price $p_{B 1}^{3}$ may not remain constrained by the price-floor. Retailer 1's optimal price is $p_{B 1}^{B R}=\frac{1-b(1-\widetilde{w})+t_{B 1}}{2}$, with $p_{B 1}^{B R} \leq \widetilde{w}$ if and only if $t_{B 1} \leq \widetilde{w}(2-b)-1+b$ : yet $t_{B 1}=\widetilde{t}$ satisfies this condition by (6). So even if a negotiation fails, all final prices remain constrained, and the status-quo profits are those of the $R P M$ case.

Second, $A$ and 1 may deviate by negotiating a higher transfer $t_{A 1}^{d}$ such that the retail price $p_{A 1}$ will be unconstrained in stage 3 . Given that the three other retail prices are $\widetilde{w}$, retailer 1 maximizes his profit by setting $p_{A 1}^{d}=\frac{1}{2}((1-a)(1-b(1-\widetilde{w}))+$ $t_{A 1}^{d}-a(2 w-\widetilde{t})$ ), and $p_{A 1}^{d} \geq \widetilde{w} \Longleftrightarrow t_{A 1}^{d} \geq t_{c}=a \widetilde{t}-(1-a)(1-b(1-\widetilde{w})-2 \widetilde{w})$. Under price-floors, the Nash condition is defined by segments: for $t_{A 1}^{d} \geq t_{c}$, both firms' profits correspond to the unconstrained price $p_{A 1}^{d}$, and for $t_{A 1}^{d} \leq t_{c}$ both firms' profits correspond to the constrained price $p_{A 1}=\widetilde{w}$. If $\alpha \leq \widetilde{\alpha}$, the maximum of this Nash condition is in $t_{A 1}=\widetilde{t} \leq t_{c}$ and leads to constrained retail prices.

No deviation in stage 1 Consider now possible deviations in stage 1. Assume that producer $B$ sets the wholesale price $\widetilde{w}$. First, it is obvious that producer $A$ would not deviate by increasing his wholesale price: as $p_{A 1}$ and $p_{A 2}$ would remain constrained the deviation would not be profitable, whether retail prices for $B$ were constrained or not. But it could be profitable for $A$ to deviate by setting in stage 1 a wholesale price $w_{A}$ sufficiently low to relax the stage 3 constraint and allow the retailers to set $p_{A i}$ above $w_{A}$ but below $\widetilde{w}$.

Consider that producer $A$ chooses such a wholesale price $w_{A}$. As this price is non-committing, due to the renegotiations in stage 2 , we can assume that $w_{A}=0\left(t_{A i}\right.$ positive). As the outcome of stage 1 is public, all the firms are aware of producer $A^{\prime} s$ deviation and adapt their strategies in stages 2 and 3 . The retail price of product $A$ is lower, so both retailers wish to reduce the price of brand $B$, which thus remains constrained: $p_{B i}=\widetilde{w}$. We consider two scenarii in turn. First, if $p_{A i}$ is not too low, there may still be a positive demand for $B$. Second, if $p_{A i}$ is low enough, product $B$ may be excluded from the market.

Deviation of producer A without exclusion of product B Assume that product $B$ still faces a positive demand: the four goods are carried, $p_{B i}=\widetilde{w}$ and 
retailers' best response prices for brand $A$ are $p_{A i}=\frac{(1-a)(1-b)-\widetilde{w}-t_{A i}+a(2-b) \widetilde{w}-a t_{B i}+b p_{A j}}{2}$.

(i) Assuming symmetry across the retailers and denoting $t_{K}^{d}$ the net transfers agreed with producer $K$, final demand for good $B$ is indeed positive iff $t_{B}^{d} \leq t_{B d e m}^{d}$, with

$$
t_{B d e m}^{d}=\frac{4(1-a)+a \alpha\left(6-2 a\left(2+a^{2}\right)+a \alpha(1-a)^{2}\right)-(1-a) b[6-5 \alpha+a(2+\alpha(3+2 a-(3+a) \alpha))]+\left(1-a^{2}\right)(2-\alpha)(1-\alpha) b^{2}}{a^{2}(2-\alpha)(\alpha((1-a) a+2 b)+2(1-b)}
$$

(ii) Given $t_{B}^{d}$, stage 2 negotiations with $A$ lead to the optimal transfers $t_{A}^{d}=$ $\frac{2 \alpha\left(1-a\left(1-t_{B}^{d}\right)\right)}{4-(2-\alpha) b}$. Producer $A$ gets a deviation profit $\Pi_{A}^{D}=\frac{4 \alpha(2-\alpha)\left(1-a\left(1-t_{B}^{d}\right)\right)^{2}}{\left(1-a^{2}\right)(1+b)(4-(2-\alpha) b)^{2}}$ where $\frac{d \Pi_{A}^{D}}{d t_{B}^{d}}>0$ locally. The deviation is profitable, i.e. $\Pi_{A}^{D} \geq \widetilde{\Pi}_{A}$, iff $t_{B}^{d}$ is higher than a threshold $t_{\text {Bpro }}^{d}$, with

$$
t_{\text {Bpro }}^{d}=1-\frac{1}{a}+\frac{(1-a)^{2}(4-(2-\alpha) b)^{2} \sqrt{(1-b+\alpha(a+b))\left(1-b+\alpha\left(b-a^{2}\right)\right)}}{(\alpha(a(1-a)+2 b)+2(1-b))(4-(2-\alpha) b)(1-a) a \sqrt{2(2-\alpha)(1-b+\alpha(b-a))}}
$$

Finally, we have to check that, given the transfers negotiated in stage 2, each retailer does not deviate by stopping selling brand $B$ in stage 3 . This implies a condition on the transfers $(i i i)$ :

- if $b \geq \frac{2}{2+\sqrt{1-a^{2}}}$ and $\alpha \leq \alpha_{1}, t_{B P C 1}(\alpha) \leq t_{B i}^{d} \leq t_{B P C 2}(\alpha)$

- if $b \geq \frac{2}{2+\sqrt{1-a^{2}}}$ and $\alpha \geq \alpha_{1}, t_{B P C 2}(\alpha) \leq t_{B i}^{d} \leq t_{B P C 1}(\alpha)$ with

$\alpha_{1}=\frac{2 a(3-a(2-a))+b\left(5-8 a+2 a^{2}-3 b\right)-\sqrt{\left[\left(2 a(3-a(2-a))+b\left(5-8 a+2 a^{2}-3 b\right)\right]^{2}-8(1-b)(2-2 a-b)\left(a^{2}(1-2 b-3 a)+3 a b+b^{2}\right)\right.}}{6 a^{3}-6 a b-2 b^{2}-a^{2}(2-4 b)}$

and

$y_{P C 1}=\frac{A+\alpha B+\alpha^{2} C}{a^{2}[2(1-b(1-\alpha))+a \alpha(1-a)]\left[2\left(4-8 b+b^{2}\left(3+a^{2}\right)\right)-\alpha\left(4\left(1-\sqrt{1-a^{2}}\right)-b\left(6+2 a^{2}-4 \sqrt{1-a^{2}}\right)+b^{2}\left(3+a^{2}\right)\right)\right]}$

$$
\begin{aligned}
& y_{P C 2}=\frac{A+\alpha B+\alpha^{2} C}{a^{2}[2(1-b(1-\alpha))+a \alpha(1-a)]\left[2\left(4-8 b+b^{2}\left(3+a^{2}\right)\right)-\alpha\left(4\left(1+\sqrt{1-a^{2}}\right)-b\left(6+2 a^{2}+4 \sqrt{1-a^{2}}\right)+b^{2}\left(3+a^{2}\right)\right)\right]} \\
& A=2(1-b)\left[2(1-b)\left((2 a+2-b)(2-b)\left(1+\sqrt{1-a^{2}}\right)+2 a^{3} b\right)-a^{2} b^{2}\left(2-b-a^{2} b\right)\right] \\
& B=-2 a^{6} b^{2}+2(1-b)(2-b)\left(1+\sqrt{1-a^{2}}\right)[b(5-3 b)+2 a(3-4 b)]-2 a^{5} b\left(2-b-b^{2}\right)
\end{aligned}
$$




$$
\begin{aligned}
& +2 a^{3}(1-b)\left(5 b^{2}+(4-2 b) \sqrt{1-a^{2}}\right)+a^{4}(-8+b(3+b)(8-b(8-3 b))) \\
& -a^{2}\left[\left(1+\sqrt{1-a^{2}}\right)\left(16-28 b+12 b^{2}\right)+(5-3 b) b^{3}\right] \\
& C=(2-b) b\left(-a^{6}+(1-b)\left(1+\sqrt{1-a^{2}}\right)(6 a+2 b)\right. \\
& +(1-b) a^{3}\left[a^{2} b(4+b)-8\left(1+\sqrt{1-a^{2}}\right)-3 b^{2}+2 b \sqrt{1-a^{2}}\right]+ \\
& a^{2}\left[\left(1+\sqrt{1-a^{2}}\right)\left(4-14 b+10 b^{2}\right)-b^{4}\right]+a^{4}\left[4\left(1+\sqrt{1-a^{2}}\right)(1-b)+b^{2}\left(9-2 b-b^{2}\right)-4 b\right]
\end{aligned}
$$

(1) Note first that if $b \geq \frac{2}{2+\sqrt{1-a^{2}}}$ and $\alpha \leq \alpha_{1}$, the constraints $(i)$, (ii) and (iii) are incompatible:

For $\alpha=\alpha_{1}, y_{P C 1}=y_{P C 2}=y_{D}$. Yet for all $\alpha \leq \alpha_{1}, y_{P C 1} \leq y_{P C 2}$ and $y_{P C 1}$ increases in $\alpha$; furthermore $y_{D}$ decreases in $\alpha$, therefore for all $\alpha \leq \alpha_{1} y_{P C 1} \leq y_{D}$ thus $y_{1} \leq y_{D}$ is incompatible with $y_{1} \geq y_{P C 1}$. This means that in that case, there are no equilibria of the subgame with the four products sold if producer $A$ sets the anticipated $x^{d}$.

$Q E D$

(2) Otherwise, i.e. if $b \geq \frac{2}{2+\sqrt{1-a^{2}}}$ and $\alpha \geq \alpha_{1}$ (with $\alpha_{1}$ such that $t_{B P C 1}\left(\alpha_{1}\right)=$ $\left.t_{B P C 2}\left(\alpha_{1}\right)\right)$ or $b<\frac{2}{2+\sqrt{1-a^{2}}}$, these conditions are compatible, but the Nash condition of the negotiation between $B$ and $i$ is maximum for a transfer less than $\widetilde{t_{B i}}$, therefore the transfer $t_{B}^{d}$ negotiated in the subgame equilibrium following the deviation of $A$ is less $\widetilde{t_{B i}}$. Yet we show easily that $\widetilde{t_{B i}} \leq t_{B p r o}^{d}$, and therefore this deviation is not profitable. This rules out any deviation without exclusion of the rival brand.

Deviation of producer A with exclusion of product B Note first that if producer $B$ anticipates that his product is going to face zero demand, he fights back by negotiating in stage 2 the lowest possible margin $t_{B i}=0$.

Consider stage 3 . Anticipating zero demand for product $B$, retailers set the following optimal prices: $p_{A i}^{2}=\frac{2-b-b^{2}+2 t_{A i}+b t_{A j}}{4-b^{2}}$.

Demand for product $B$ is indeed zero at both retailers' if and only if:

$$
\frac{-1+b+p_{A 2}}{b}+\frac{(1-b)(1-\widetilde{w})}{a b} \leq p_{A 1} \leq 1-b\left(1-p_{A 2}\right)-\frac{(1-b)(1-\widetilde{w})}{a} .
$$

Besides, no retailer wishes to deviate by selling product $B$ as well iff

$$
t_{A i} \leq t^{D}\left(t_{A j}\right)
$$

In other words, the only way for producer $A$ to induce an equilibrium with exclusion of $B$ is to set a unit price sufficiently low for both conditions (8) and (9) to hold. Whenever these two conditions hold, there exists a downstream subgame 
equilibrium with exclusion of product $B$. If the deviation by $A$ led to this subgame equilibrium, it would be profitable for $A$, for some values of the parameters, and destroy the $R P M$ equilibrium in that zone. ${ }^{34}$ Yet whenever this subgame equilibrium exists, there exists also another downstream equilibrium without exclusion of product $B$, where both retailers sell both goods and set the following prices for product $A$ : $p_{A i}^{4}=\frac{(1-a)(2-b(1+b))+2 t_{A i}+t_{A j}+a\left(4-b^{2}\right) \widetilde{w}}{4-b^{2}} \cdot{ }^{35}$ In that case, producer $A^{\prime} s$ profit is less than in the $R P M$ equilibrium, as shown in the previous section.

Formally, we have proved that the following strategies and beliefs form a symmetric contract equilibrium for $\alpha \leq \widetilde{\alpha}$ : in stage 1, both producers set the unit wholesale price $\widetilde{w}$; in stage 2 , the four pairs negotiate the transfers $\widetilde{t}$; in stage 3 , both retailers set retail price $\widetilde{w}$ for both products; all firms believe that in any subgame where one producer (say $B$ ) has chosen the unit wholesale price $\widetilde{w}$ and the other one (say $A$ ) has deviated to $w_{A}=0$, and the issue of the negotiations in stage 2 leads to net transfers $t_{B i}=0$ and $t_{A i}$ such that $t_{A i} \leq t^{D}\left(t_{A j}\right)$ where $\{i, j\}=\{1,2\}$, then each retailer will choose to sell both products with prices $p_{A i}^{4}$ and $p_{B i}=\widetilde{w}$.

\section{A.3.2 The corner price-floor equilibrium}

For $\alpha \geq \widetilde{\alpha}$, the producers have to increase the price-floors above $\widetilde{w}$ in order to saturate the constraint (6). As long as this leads to the optimal negotiated transfers (2), the minimum symmetric wholesale price which satisfies this constraint is $\bar{w}=\frac{1-a \alpha-b(1-\alpha)}{2-\alpha(1+a-b)-b}$. We show that setting this price in stage 1 sustains an equilibrium for $\widetilde{\alpha} \leq \alpha \leq \bar{\alpha}=\frac{2-b}{3-b}$, with producers' equilibrium profits $\overline{\Pi_{K}}=\frac{2(1-a) \alpha(1-\alpha)}{(1+a)(1+b)(2-\alpha(1+a-b)-b)^{2}}$.

Assume that $B$ sets $w_{B}=\bar{w}$ and $A$ deviates by setting $w_{A} \leq \bar{w}$. If the transfers are such that $t_{K i} \leq t_{K i l}=(2-b) w_{K}-1+b$, all retail prices are constrained in stage 3 , even in case of a failure in one negotiation, and producer $A$ anticipates the profit $\Pi_{A}^{d}=$ $\frac{2\left(1-a(1-\bar{w})-w_{A}\right)\left((2-b) w_{A}-1+b\right)}{\left(1-a^{2}\right)(1+b)}$, which is maximum for $w_{A}^{d}=1-\frac{1}{2(2-b)}-\frac{a(1-\alpha)}{2(2-\alpha(1+a-b)-b)}$. If $\alpha \leq \bar{\alpha}, w_{A}^{d} \geq \bar{w}$ and no deviation of this type is profitable for $A$. However if $\alpha \geq \bar{\alpha}$, $w_{A}^{d} \leq \bar{w}$. If $A$ sets $w_{A}^{d}$ in stage 1 , the resolution of the Nash condition between producer $A$ and his retailers leads to a corner solution. The unique subgame equilibrium of the game is as follows: each pair $(A, i)$ negotiates the corner transfer $t_{A i l}=(2-b) w_{A}^{d}-1+b$,

\footnotetext{
${ }^{34}$ Tedious calculations show that the deviation is profitable for $\alpha$ less than a threshold lower than $\alpha_{d}(a, b)$.

${ }^{35}$ Comparing the retailers' profits in the two subgame equilibria shows that both retailers are better off if the four products are carried than if $B$ is excluded. The subgame equilibrium with exclusion of $B$ is therefore Pareto-dominated by the one without exclusion of $B$.
} 
each pair $(B, i)$ negotiates the interior transfers $t_{B i}^{*}=\frac{\alpha\left(\bar{w}+a\left((1-b) w_{A}^{d}-1+b\right)\right)}{1-(1-\alpha) b}$, and the retail prices set in stage 3 are $p_{A i}=w_{A}^{d}$ and $p_{B i}=\bar{w}$. Producer $A^{\prime} s$ profit is then larger than $\overline{\Pi_{K}}$ : this deviation is profitable for any $\alpha \geq \bar{\alpha}$.

Yet if $\alpha \leq \bar{\alpha}$, no deviation is profitable. First, if both producers set the unit price $\bar{w}$, and second stage negotiations lead to the transfers (2), the four retail prices will be constrained and equal to $\bar{w}$. Second, if both producers set the unit price $\bar{w}$, the only subgame equilibrium outcome defines the transfers (2). Third, it cannot be profitable for $A$ to set a higher unit price, as retail prices would remain constrained and $A^{\prime} s$ profit would be lower than $\overline{\Pi_{K}}$. Finally, using the same method as in section $A 3.1$ we show that it is not profitable to deviate by setting a lower wholesale price such that transfers are set to (2) and retail prices for $A$ are not constrained. Here excluding $B$ would never be possible, and the deviation without exclusion of $B$ would give $A$ a profit lower than $\overline{\Pi_{K}}$ for $\widetilde{\alpha} \leq \alpha \leq \bar{\alpha}$.

\section{A.3.3 The corner transfer equilibrium}

The unit price $w_{A}=w_{B}=\widehat{w}$ sustains an equilibrium for $\bar{\alpha} \leq \alpha \leq \widehat{\alpha}=\frac{2(2-b)}{4-b}$ where each pair negotiates limit transfers $\widehat{t}=(2-b) \widehat{w}-1+b$. First, if both producers have set the unit price $\widehat{w}$ in stage 1 , and all other pairs' negotiations outcomes in stage 2 are the optimal transfer $\widehat{t}$, the unique solution of the Nash condition of the negotiation for the last pair is the corner solution $\widehat{t}$ as long as $\alpha \leq \widehat{\alpha}$. Second, we show that if producer $B$ chooses $\widehat{w}$ in stage 1 , the best response of $A$ is to set the same unit price.

\section{A.4 Welfare effects}

Consumer surplus is $S(q)=U(q)-\sum_{K, i} p_{K i} q_{K i}$. As the firms' costs are normalized to zero, total welfare is thus $W=U(q)=\sum_{K, i} q_{K i}-\frac{1}{2} \sum_{K, i} q_{K i}^{2}-a \sum_{i} q_{A i} q_{B i}-b \sum_{K} q_{K 1} q_{K 2}-$ $c \sum_{K} q_{K 1} q_{L 2}:$ if the four prices are equal, it increases in the total quantity sold ${ }^{36}$, i.e. decreases in the retail price. Comparisons across different equilibria are straightforward.

\footnotetext{
${ }^{36}$ As long as the total quantity is less than $\frac{1}{(1+a)(1+b)}$, that is the maximum quantity sold when the four prices are zero.
} 


\section{A.5 Robustness and extensions}

\section{A.5.1 Two-Part Tariffs}

With two-part tariffs, profits are, with $P$ the vector of retail prices:

$$
\begin{aligned}
\Pi_{K} & =t_{K i} D_{K i}(P)+F_{K i}+t_{K j} D_{K j}(P)+F_{K j} \\
\Pi_{i} & =\left(p_{K i}-t_{K i}\right) D_{K i}(P)-F_{K i}+\left(p_{K j}-t_{K j}\right) D_{K j}(P)-F_{K j}
\end{aligned}
$$

No restriction Without the law, in stage 2, each pair maximizes the Nash objective over two variables: $t_{K i}$ and $F_{K i}$. There are thus eight first-order conditions, and the resolution of this system with symmetry across the retailers leads to a subgame equilibrium with zero margins for the producer $\left(t_{K i}=0\right)$ and franchise fees equal to $F_{K i}^{T P}=\frac{\alpha(1-a)(1-b)}{(1+a)(1+b)(2-b)^{2}}$. As with linear tariffs, there is no commitment in stage 1. The symmetric equilibrium retail prices are $p_{K i}^{T P}=\frac{1-b}{2-b}$ and the profits are as follows:

$$
\begin{aligned}
\Pi_{K} & =2 F_{K i} \\
\Pi_{i} & =\frac{2(1-b)(1-\alpha(1-a))}{(1+a)(1+b)(2-b)^{2}}
\end{aligned}
$$

Total profit is lower with two-part tariffs than with linear tariffs, except for $\alpha \in$ $\left[\frac{2 b(2-b)}{2-b^{2}-2 a(1-b)}, 1\right]$ (this interval exists only for low values of $a$ and $b$ ): Two-part tariffs suppress double margin; yet when $\alpha$ is not too high, double margin increases joint profits by relaxing competition at both levels and increasing retail prices towards the joint-profit maximizing price $1 / 2$. Therefore suppressing double margin hurts joint profit, except when double margin drives prices too high, which happens when $a$ and $b$ are low and $\alpha$ is high. Producers' share of total profit is $\alpha(1-a)$ : it increases in their bargaining power $\alpha$ and decreases in the intensity of upstream competition $a$.

RPM equilibria Assume that producers impose $R P M$ prices $w_{A}$ and $w_{B}$ in stage 1. In stage 2, assuming symmetry across the retailers, the system of the eight Nash conditions is underdetermined, and yields the following optimal franchise fees as functions of the variable parts $t_{K}$ and $t_{L}$ :

$$
F_{K}^{\circ}\left(w_{K}, w_{L}, t_{K}, t_{L}\right)=\frac{\left(1-a-w_{K}+a w_{L}\right)\left(\alpha\left(w_{K}-a w_{L}-b t_{K}+a t_{L}\right)-(1-b) t_{K}\right)}{\left(1-a^{2}\right)(1+b)}
$$

For each pair $\left(w_{A}, w_{B}\right)$ there exists a continuum of equilibria of the subgame. Among these, the joint profit of each pair $(K, i)$ is constant, but its sharing differs: 
Producer $K$ 's profit increases whereas retailer $i^{\prime}$ s decreases with $t_{K}$. The reason is that the producer's status-quo profit increases (and the retailer's decreases) in $t_{K}$.

In stage 1 , the producers anticipate one of the subgame equilibria. For each anticipated $\left(t_{A}, t_{B}\right)$, there exists a unique $\left(w_{A}, w_{B}\right)$ such that if the producers anticipate the subgame equilibrium outcomes $\left(t_{A}, t_{B}, F_{A}^{\circ}, F_{B}^{\circ}\right)$, where $F_{K}^{\circ}$ are given by $(10)$, then setting the $R P M$ prices $\left(w_{A}, w_{B}\right)$ in stage 1 is an equilibrium strategy. Finally, there is a continuum of symmetric equilibria of the game. Equilibrium final prices are defined as a function of $t$, the symmetric variable part of the wholesale tariff for $\alpha>0$ :

$$
w^{\circ}(t)=\frac{1}{2}\left(1-t \frac{b+\alpha(a-b)}{\alpha(1-a)}\right)
$$

with $t$ such that $0 \leq t \leq w^{R P M}$, i.e. for $0 \leq t \leq t_{R P M}$, with $t_{R P M}=\frac{\alpha(1-a)}{b+\alpha(2-a-b)}$. As $t_{R P M}$ decreases with $\alpha$, the set of equilibrium retail prices shrinks when producers' bargaining power increases.

Note that $w^{\circ}(t)$ decreases in the variable part of the net transfer $t$ (as $\left.\frac{b+\alpha(a-b)}{\alpha(1-a)} \geq 0\right)$. Joint profit is maximum when retail prices are at the monopoly price $p^{M}=1 / 2$, and decreases in $t$. Furthermore, given $\alpha$, the different equilibria are not equivalent in terms of profit sharing: producers' profits $\Pi_{K}=\frac{\left(\alpha(1-a)+t(a \alpha+b(1-\alpha))^{2}\right.}{2 \alpha\left(1-a^{2}\right)(1+b)}$ increase in $t$, whereas retailers' profits as well as joint profits decrease in $t$. That the equilibrium with two-part tariffs does not necessary maximize joint profit is an original result. The intuition is as follows. Consider stage 1. If the producers anticipate that the stage 2 negotiations will lead to $t=0$ and the matching fixed fees, they are going to be paid through the fixed fee only and the best the can do is to maximize the joint profit, and the equilibrium $R P M$ price is therefore $w=1 / 2$. Yet if they anticipate a positive variable part of the transfer, then each producers' status-quo profit decreases with its RPM price, whereas the retailers' status-quo profits increase with it: Totally differentiating producer $A^{\prime} s$ status-quo profit given $\left(t_{A}, t_{B}\right)$ and $w_{B}$ shows that $\frac{d \Pi_{A}^{s q}}{d w_{A}}$ is negative in an interval around the equilibrium values. This explains why, when both producers anticipate positive $t_{K}$, the equilibrium $R P M$ price does not maximize total industry profit. Note that this is not only a consequence of upstream competition, as it would also happen with an upstream monopoly $(a=0)$ : for $\alpha<1$, there would also exist a continuum of equilibria with $R P M$ prices that would not maximize joint profit.

Note that the $R P M$ equilibrium with linear tariffs $\widetilde{w}$ is always sustainable as an equilibrium retail price under $R P M$ with two-part tariffs. In that equilibrium, joint profit is the same than with linear tariffs, but retailers get more and producers less. 
Price-floor equilibria Consider now that $w^{\circ}(t)$ is only a price-floor. In stage 3 , if her competitor sets prices $p_{K j}$ and if the issue of stage 2 negotiations with her two suppliers led to unit prices $t_{K}$, retailer $i$ 's best response prices are $p_{K i}=\frac{1-b+t_{K}+b p_{K j}}{2}$. This price is below the price-floor, which will be binding indeed, if and only if $t \leq t_{P F}$, with

$$
t_{P F}=\frac{\alpha b(1-a)}{b(2-b)+\alpha(2-b(2+a-b))}
$$

Therefore the minimum price that is sustainable with price-floor is

$$
w^{\circ}\left(t_{P F}\right)=\frac{1}{2}\left(1-\frac{b(b+\alpha(a-b))}{(2-b) b+\alpha(2-b(2+a-b))}\right)
$$

The interval of equilibrium retail prices with two-part tariffs and a price-floor is $\left[w^{\circ}\left(t_{P F}\right), 1 / 2\right]$. It is smaller than under $R P M$. As $t_{P F}$ increases in $\alpha$, this interval shrinks when $\alpha$ increases. For $\alpha=0$, the lowest price in equilibrium is $w^{\circ}\left(t_{P F}\right)=\frac{1-b}{2-b}$, whereas it is $w^{\circ}\left(t_{P F}\right)=\frac{1-a b}{2-a b}$ for $\alpha=1$. Note that for all $\alpha, w^{\circ}\left(t_{P F}\right) \geq \frac{1-b}{2-b}$ : retail prices are higher than in the no-restriction equilibrium. Finally, retail prices of the linear tariff price-floor equilibria are sustainable as price-floor equilibria with two-part tariffs as long as they are below $1 / 2$.

Producers' profit is lower with two-part tariffs than with linear tariffs (even for $\left.t=t_{P F}\right)$. However, with two-part tariffs, producers' profit is always higher with pricefloor than without. Retailers' situation is more ambiguous: the price-floor equilibrium with $t_{K}=0$ gives them higher profit than the no-restriction equilibrium with two-part tariffs, but the equilibrium with $t_{K}=t_{P F}$ gives them lower profits.

Upstream deviations We check here that producers do not deviate from the price-floor strategies. The only deviation that has not been ruled out by the RPM analysis is one where a producer (say $A$ ) deviates by setting a lower price-floor such that retail prices are unconstrained in stage 3 , and these deviations are equivalent to setting $w_{A}=0$ in stage 1 (see a detailed analysis in the linear tariffs case).

In that case, prices remain constrained at $w_{B}$ for $B$ in stage 3 but not for product $A$; Solving the corresponding Nash conditions gives the optimal tariffs in stage 2: $t_{K i}=0$. The deviation profit for $A$ is thus $\Pi_{A}^{d}=\frac{2 \alpha(1-b)\left(1-a\left(1-t_{B}^{d}\right)\right)^{2}}{\left(1-a^{2}\right)(1+b)(2-b)^{2}}$ where $t_{B}^{d}$ is the transfer negotiated between $B$ and a retailer in stage 2 . There is a continuum of subgame equilibria where the negotiation outcomes for $B$ are given by $F_{B}^{d}=g\left(w_{B}, t_{B}^{d}\right)$. Among these, the subgame equilibrium with $t_{B}^{d}=0$ leads to $\Pi_{A}^{d}=\frac{2 \alpha(1-b)(1-a)}{(1+a)(1+b)(2-b)^{2}}$ less than $\Pi_{K}^{P F}(t=0)$, the minimum profit $A$ gets in the price-floor equilibrium: the deviation is not profitable. The strategies defined thus implement an equilibrium. 


\section{A.5.2 Discrimination}

Consider that producers and retailers now negotiate in stage 2 over a total transfer $t_{K i}-f_{K i}$, where the price-floor is $t_{K i}$.

Assume that retail prices are constrained. In stage 2, each pair negotiates over two variables $t_{K i}$ and $f_{K i}$ so that eight first-order conditions determine the equilibrium outcomes: $t_{K i}^{\diamond}=1-\frac{1}{2-\alpha a-(1-\alpha) b}$ and $f_{K i}^{\diamond}=\frac{(1-\alpha)(1-b)}{2-\alpha a-(1-\alpha) b}$. In stage 3, retailer $i^{\prime} s$ best response prices are $p_{K i}^{B R}$. This price is always larger than the individual price-floor $t_{K i}^{\circ}$ which is therefore not binding.

Producers thus have to raise the price-floor in order to constrain the retailers. The minimum binding price-floor is $\overline{t_{K i}^{\circ}}=\frac{1-a \alpha-b(1-\alpha)}{2-\alpha(1+a-b)-b}$, such that $p_{K i}^{B R}=\overline{t_{K i}^{\circ}}$ for both retailers. The corresponding $\overline{f_{K i}^{\diamond}}$ is inferred from the first-order conditions of stage 2 negotiations: $\overline{f_{K i}^{\diamond}}=\frac{(1-a) \alpha}{2-\alpha(1+a-b)-b}$. This does not define an equilibrium as there is always a unilateral incentive for a pair $(K, i)$ to deviate towards a higher price-floor. Furthermore, any price-floor above this level will also fail to sustain an equilibrium.

As there is renegotiation in stage 2 , no binding price-floor can sustain an equilibrium. Therefore there is no constrained equilibrium.

\section{A.5.3 Ex-post observability of the bargaining outcome}

Assume that $a=0$ (upstream monopoly) and the outcome of each negotiation is published at the end of stage 2 . Without legal restriction, in stage 3 , each retailer knows the issue of all negotiations, so that the retail prices are given by $p_{i}=\frac{2-b(1+b)+2 t_{i}+b t_{j}}{4-b^{2}}$. In stage 2 , if there is a failure in negotiation between the producer and retailer 1 , retailer 2 sets the monopoly price $\frac{1+t_{2}}{2}$ which is larger than the price he sets without EPO. Quantity sold thus decreases, as does the producer's status-quo profit which is now $\frac{\left(1-t_{2}\right) t_{2}}{2}$; retailer 1's status-quo profit is still 0 . As a consequence, the transfers negotiated are lower than with secret contracts and retail equilibrium prices as well.

Under the law and without $E P O$, the producer would choose $\widetilde{w}=\frac{1}{2}$ for $\alpha \leq \widetilde{\alpha}=$ $\frac{b}{(1+b)}$. EPO leads to different status-quo profits in stage 2: If the unit price set in stage 1 is $w$, when negotiation breaks with retailer $i$, the other retailer may set his price above $w$. There exists $\left\{\underline{w^{o}}, \overline{w^{o}}\right\}$ such that

(i) if $w \leq \underline{w}^{o}$, retailers' pricing strategies are not constrained in stage $3\left(p_{i} \geq w\right)$;

(ii) if $\underline{w^{o}} \leq w \leq \overline{w^{o}}$, retailers' pricing strategies are constrained in stage 3 but not if one negotiation breaks: If negotiation breaks between $A$ and 1 , retailer 2 will set the optimal monopoly price $p_{2}^{1}=\frac{1+t_{2}}{2} \geq w$, and the producer's status-quo profits 
is $\Pi_{P}^{1}=t_{2}\left(\frac{1-t_{2}}{2}\right)$. The negotiations determine optimal net transfers such that the producer's profit is concave in $w$.

(iii) if $w \geq \overline{w^{o}}$ retailers' pricing strategies are constrained in stage 3 and in the status-quo; the optimal net transfers are thus $t_{i}=\frac{\alpha w}{1-b(1-\alpha)}$ and the producer's profit decreases in $w$ for $w \geq \overline{w^{o}}$.

We show that $0 \leq \underline{w^{o}} \leq \overline{w^{o}} \leq 1$ and $\overline{w^{o}} \geq 1 / 2$. Furthermore $\underline{w^{o}} \leq 1 / 2$ for all $\alpha \leq \alpha_{\lim }=\frac{b\left(2-b-b^{2}\right)}{2-b^{2}-b^{3}}$, with $\alpha_{\lim } \geq \widetilde{\alpha}$.

For all $\alpha \leq \alpha_{\text {lim }}$, if the producer sets the wholesale price $w=1 / 2$, retailers are constrained in equilibrium but not in the status-quo case. The producer's profit is thus larger than his unconstrained profit. Furthermore, it increases in $w$ for $w \leq \frac{1}{2}$, so that the optimal binding wholesale price is in $\left.] \frac{1}{2}, \overline{w^{o}}\right]$. The producer is better off with a binding wholesale price larger than $\widetilde{w}=\frac{1}{2}$ and in a wider zone than without EPO (at least for $\alpha \leq \alpha_{\text {lim }}$ which is larger than $\widetilde{\alpha}$ ). 